\title{
Abstractionist versus episodic theories of repetition priming and word identification
}

\author{
PATRICIA L. TENPENNY \\ Loyola University, Chicago, Mlinois
}

\begin{abstract}
This paper reviews research relevant to the question of whether words are identified through the use of abstract lexical representations, specific episodic representations, or both. Several lines of evidence indicate that specific episodes participate in word identification. First, pure abstractionist theories can explain short-term but not long-term repetition priming. Second, long-term repetition priming is sensitive to changes in surface features or episodic context between presentations of a word. Finally, long-term priming for pseudowords is also difficult for pure abstractionist theories to explain. Alternative approaches to word identification are discussed, including both pure episodic theories and theories in which both episodes and abstract representations play a role.
\end{abstract}

Researchers have repeatedly demonstrated that word identification is facilitated on the second presentation of a word. This phenomenon, known as repetition priming (or savings), occurs in a variety of tasks believed to involve word identification processes. ${ }^{1}$ Repetition speeds lexical decisions (e.g., Scarborough, Cortese, \& Scarborough, 1977), word naming (e.g., Durso \& Johnson, 1979), and the reading of sentences (e.g., Kolers \& Ostry, 1974) and longer text (e.g., Kolers, 1976). Repeated words are also more likely to be correctly identified on a perceptual identificationi test, in which a word is shown for a very brief duration before being masked (e.g., Jacoby \& Dallas, 1981).

There has been considerable disagreement about the nature of repetition priming in word identification tasks. At the heart of the debate is the question of whether the effect of repetition on word identification is mediated by abstract representations, by specific episodic representations, or both. The goal of this paper is to provide a critical review of the evidence relevant to this question.

Distinctions between general and specific information have provoked lively discussions throughout the field of cognitive psychology. General and specific knowledge are often assumed to be used for different purposes and to be very different in nature as well. Two types of distinctions between general and specific information have been made. First, general knowledge of facts and skills

Preparation of this paper was partially supported by a Summer Research Stipend from Loyola University of Chicago. I thank Kim Kirsner, Betty Ann Levy, J. W. Whitlow, and an anonymous reviewer for their insightful reviews. I am especially grateful to Jim Neely for numerous valuable comments. I also thank Gordon Logan for helpful e-mail discussions. Finally, thanks to Ed Shoben for comments on an earlier version of this paper. Correspondence should be addressed to P. L. Tenpenny, Department of Psychology, Loyola University of Chicago, 6525 North Sheridan Road, Chicago, IL 60626 (e-mail: ptenpen@luc.edu). has been distinguished from specific knowledge of episodes in which those facts and skills are learned or used. Tulving (1972), for example, proposed that semantic and episodic information are stored in separate memory systems that operate by different principles (Tulving, 1983, 1985, later added a third system for procedural information). Thus, for instance, one's general knowledge about cats, about Persian cats, and about one's pet Persian cat would be stored in the semantic memory system, whereas the memory of one's last encounter with one's pet cat would be stored in the episodic system. According to this type of general-specific distinction, then, information about episodes is fundamentally different from other information and may reside in a different memory store.

Second, general knowledge about concepts has been distinguished from specific knowledge about instances of concepts. For example, for many years it was thought that the classification of new members of a category only made use of category-level information and was not influenced by information about individual exemplars (Posner \& Keele, 1968; Reed, 1972). Returning to the cat example, this distinction implies that, in most cases, knowledge specific to Persian cats would not be used to answer questions about cats in general, and knowledge specific to one's own Persian cat would not be used to answer questions about Persian cats in general. Thus, different levels of generality are distinguished.

More recent evidence, however, has forced theorists to reconsider both of the ways in which general and specific information have been distinguished. Numerous experiments have shown effects of specific episodes on tasks thought to tap more general knowledge (e.g., Anderson \& Ross, 1980; Graf \& Schacter, 1985; Jacoby, 1983a, 1983b; Jacoby \& Dallas, 1981; Tulving, Schacter, \& Stark, 1982). In addition, many studies have demonstrated the use of specific examples in tasks pre- 
viously thought to rely on generalizations (e.g., Brooks, 1978; Medin, Altom, Edelson, \& Freko, 1982; Medin \& Schaffer, 1978; Ross, 1984, 1987). These results have served as the catalyst for the development of new theories that ascribe a much greater role to specific information than before (e.g., Logan, 1988; Medin \& Schaffer, 1978; see Jacoby \& Brooks, 1984, for an extensive review).

Some accounts go so far as to blur both types of distinctions between general and specific information. According to these accounts, tasks previously thought to rely on generalizations may instead make use of representations of individual episodes (Hintzman, 1986; Jacoby, 1983a, 1983b; Jacoby \& Brooks, 1984; Jacoby \& Hayman, 1987; Jacoby \& Witherspoon, 1982; Kolers \& Roediger, 1984). Although the existence of generalizations - whether over episodes or over examples-is not necessarily denied, they are not accorded special status, nor are they assumed to require a different form of representation. For example, in distributed models such as that of McClelland and Rumelhart (1985), episodes, exemplars, and category-level information can coexist in the same set of connection weights, and the level of information retrieved depends on what cues are given and what the particular weights are.

To summarize, some theorists (e.g., Tulving, 1983) have argued that the way in which specific episodes are represented differs fundamentally from the way in which other kinds of information are represented. Additionally, general knowledge about concepts has been distinguished from specific knowledge about instances of concepts. 'The first distinction concerns forms of representation, whereas the second concerns levels of generality.

With this background in mind, word identification theories can be classified into four groups. First, pure abstractionist theories posit fundamentally distinct forms of representation for episodes and lexical entries, with only the lexical representations participating in word identification. These models posit a separate representation for each word in the lexicon, either alone (e.g., Becker, 1980; Johnson \& Pugh, 1994; Morton, $1969,1979)$ or in combination with a set of phonological recoding rules (e.g., Coltheart, 1980; Coltheart, Curtis, Atkins, \& Haller, 1993). In pure abstractionist models, the presentation of a word activates or retrieves its abstract lexical entry, which does not include information specific to an occurrence of a word. With time, the lexical entry returns to its original state. However, if a word is repeated while its lexical entry is still in a state of heightened accessibility, the identification process has a "head start." Consequently, repeated words are identified more rapidly. (See Carr \& Pollatsek, 1985, for an extensive review of the models.) Note that the pure abstractionist approach does not deny the existence of episodic memory for words; rather, the claim is that episodic memories do not influence word identification.

Alternatively, the weakly abstractionist ${ }^{2}$ approach assumes that identification occurs primarily through the activation of abstract lexical representations but allows specific episodes to sometimes play a role. In most cases, repetition priming would be attributed to the enhanced accessibility of abstract lexical entries. However, specific, detailed episodes could be used (for example) to identify repeated nonwords, which lack lexical entries, or to identify a word presented in an unusual font or handwriting.

A third possibility is to adopt a weakly episodic approach, in which the same form of representation would be used for episodes (e.g., a particular occurrence of a word) and for generalizations formed by abstracting over episodes (e.g., a "prototype" representation of a word). For example, one weakly episodic way to represent a lexical entry would be as the overlap among a number of episodes containing a particular word, as in distributed models of memory (e.g., McClelland \& Rumelhart, 1985). In such models, each presentation of a word modifies the weights on connections among the units so as to improve the network's response to the word. As the network is exposed to other stimuli, the improvement becomes attenuated through interference. However, if a word is repeated while there is still relatively little interference from other items, the network's response to the repeated word will be enhanced, and repetition priming will occur.

The specificity of the activation pattern evoked by a repeated word depends largely on the similarity between the current presentation and the previous presentation. If the current presentation is highly similar to the previous presentation, then the network should produce a pattern that corresponds to that specific earlier presentation. On the other hand, if the current presentation is not highly similar to the previous presentation, then the network would be more likely to produce a pattern that roughly corresponds to a lexical entry. Hence, the crucial difference between the weakly abstractionist view and the weakly episodic view is that the weakly abstractionist view posits fundamentally different forms of representation for episodes and lexical entries, whereas the weakly episodic view holds that they differ only in level of generality.

Finally, the pure episodic approach asserts that words are always identified through the use of specific prior episodes that include those words (Jacoby, 1983a, 1983b; Jacoby \& Brooks, 1984; Jacoby \& Witherspoon, 1982; Kolers, 1975, 1976; Kolers \& Ostry, 1974; Kolers \& Roediger, 1984; Logan, 1988, 1990). According to this approach, repetition priming arises from the fact that recent episodes are generally more accessible than are older episodes. Thus, like the pure abstractionist view, the pure episodic view proposes that the same kinds of representations are used to identify primed and unprimed words; however, the pure episodic approach holds that the representations are specific episodes rather than abstract lexical entries.

After describing the most commonly used word identification tasks, I will consider four lines of evidence relevant to the abstractionist-episodic debate. First, I will review studies that have examined the longevity of rep- 
etition priming in word identification. Then, I will examine research that has investigated the effects of details of specific occurrences of words. Next, I will address differences in the identification of words and pseudowords. Finally, I will briefly discuss priming between words that are not identical but share a base morpheme.

\section{MAJOR TASKS}

Although researchers have employed a variety of tasks to investigate reading and word identification, most have used the ones described below. Repetition priming is said to have occurred if performance on these tasks is faster or more accurate for previously seen materials than for new materials.

In the perceptual identification task, a word is flashed on a computer screen for a brief duration (say, $33 \mathrm{msec}$ ) before being masked. The subject either types the word or says it aloud. A premask is sometimes used to make the task more difficult. Because tachistoscopes were originally used for this task, it is sometimes referred to as tachistoscopic identification.

The lexical decision task requires the subject to decide very quickly whether a presented string of letters forms a word. A response is made by pressing one key if the string is a word and another key if the string is not a word. Subjects are usually instructed to respond as quickly as possible but to keep their errors to a minimum. The primary dependent measure is response time (RT) for word trials on which correct responses are made; however, error rates are also analyzed.

In the naming task, subjects are asked to pronounce a presented word as quickly as possible. The primary dependent measure is the time taken to initiate a correct pronunciation, but error rates are also examined. In addition, a qualitative analysis of the responses made on error trials is sometimes done.

The fourth common task is rereading, in which the experimenter records the time taken to read aloud or silently a text passage, a sentence, or a list of words.

Finally, subjects may be asked to read a passage silently, crossing out any errors that they find. This proofreading task has been used primarily by Levy and her colleagues (e.g., Levy \& Begin, 1984). Both accuracy and reading time are recorded.

This review does not include some widely used indirect tests of memory for words, such as the word stem completion task (Warrington \& Weiskrantz, 1974) and the two versions of the word fragment completion task (Tulving et al., 1982; Warrington \& Weiskrantz, 1968). These tasks have been excluded because, although word identification processes probably contribute to their performance, it seems likely that they also invoke problemsolving processes that are seldom used in reading. In addition, conscious recollection probably plays a larger role in performance on these tasks (e.g., Jacoby \& Whitehouse, 1989). However, because the word identification tasks included in this review either require the subject to respond very quickly or present the stimuli for very brief durations, the influence of conscious recollection on these tasks should be relatively small.

\section{EVIDENCE}

\section{The Persistence of Repetition Priming}

Data from experiments employing the masked and unmasked form priming paradigms indicate that repetition of a word can produce two distinct types of repetition priming with differing lifespans (Forster, 1987; Forster \& Davis, 1984; Humphreys, Besner, \& Quinlan, 1988; Humphreys, Evett, Quinlan, \& Besner, 1987; Rajaram \& Neely, 1992). In the basic form priming paradigm, the test trial includes a prime that is displayed just prior to the target and in the same location. Lowercase letters are used for the prime, and uppercase letters are used for the target. Usually no response is made to the prime. For the present purposes, the most relevant experiments are those in which the researchers varied whether the prime and the target were the same item. In the masked form priming paradigm, the prime is displayed very briefly and is preceded by a mask (a word, a nonword, or a string of Xs) so that it cannot be identified. In the unmasked form priming paradigm, the prime is not masked and is displayed for a longer duration (sometimes in a separate study phase), allowing the prime to be identified.

Short-term repetition priming occurs in the masked form priming paradigm when the prime and target are not perceived as distinct events (Humphreys et al., 1988; Humphreys et al., 1987). Subjects may detect the facilitation caused by the prime, but because the prime and target merge into a single event, they attribute the facilitation to some other source (Jacoby \& Whitehouse, 1989). This type of priming disappears if more than a few items intervene between the prime and target (Forster \& Davis, 1984).

In contrast, the type of repetition priming that occurs when the prime and target are experienced as separate events can be extraordinarily persistent. Using the perceptual identification task, significant priming has been observed after delays of 1 day (Jacoby \& Dallas, 1981) and 4 days (Jacoby, 1983a). In addition, lexical decision priming has been found following a 2-day delay (Scarborough et al., 1977). More dramatically, faster rereading times for geometrically transformed text have been obtained after retention intervals ranging from a week (Masson, 1984) to a month (Kolers \& Ostry, 1974) to over a year (Kolers, 1976).

Ultimately, a successful theory of word identification must be able to explain both short-term and long-term repetition priming effects. Theories that attribute repetition priming to a temporary increase in the accessibility of a word's abstract lexical representation handle shortterm effects more readily than long-term effects. For example, according to Morton's logogen model (Clarke \& Morton, 1983; Jackson \& Morton, 1984; Morton, 1979), the visual presentation of a word results in the lowering of the threshold of the word's visual input logogen. If a second visual presentation of the word occurs before the 
logogen's threshold returns to normal, it will be exceeded more rapidly, producing repetition priming. As another example, McClelland and Rumelhart's (1981) interactive activation model accounts for repetition priming by assuming that units lose their activation gradually. Thus, repetition priming occurs if the activation of a word unit has not yet returned to its resting level by the time the word is repeated. A third example is Taft and Forster's (1976) lexical search model, in which the lexicon is ordered by frequency and recency; hence, recently presented words are located more rapidly.

In all of these models, the increase in accessibility that produces repetition priming is assumed to be fairly short lived - on the order of seconds or (at most) minutes. There are two reasons why the models make this assumption, both of them consequences of the large number of words that a person sees each day. First, if lexical units could remain highly accessible for long periods of time, the number of primed units would soon become implausibly large. For example, if logogen thresholds could be lowered for as long as a day, hundreds or thousands of logogens would be primed at any given time. Consequently, theorists who attribute priming to abstract representations must assume that this enhanced accessibility is fleeting.

Second, in models that posit competition among lexical units, words encountered between the first and the second presentation of a target word make it impossible for a single presentation to have a lasting impact on performance. In the lexical search model, for example, the intervening words would push the target farther back in the queue. Similarly, in the interactive activation model, the activation of the word-level unit for the target would soon be wiped out by inhibition from other word units (see Rueckl, 1990, for a very similar argument).

Thus, although theories that attribute priming to abstract representations can handle short-term repetition priming effects, long-term effects seem to require the positing of additional mechanisms. This seems to rule out a pure abstractionist account. The obvious alternatives are weakly abstractionist and weakly episodic theories that attribute short-term priming to lexical representations and long-term priming to episodes. Nevertheless, a pure episodic account may be viable. At first, one might expect that pure episodic models will fare no better than pure abstractionist models, because they too must explain why representations of a given type have short-lived effects in some cases and have long-lived effects in others. However, one of the basic findings that episodic models must explain is that forgetting rates vary depending on how memory is measured. Consequently, episodic theorists must solve this more general problem anyway. To the extent that they succeed, they may also be able to account for short- and long-term effects on word identification tasks.

Still, other potential problems remain. For example, in distributed memory models, the ability to recover an episode can be severely disrupted by a relatively small number of subsequent episodes. This phenomenon, known as catastrophic interference, occurs because the connection weights are modified as each new episode is experienced, eventually causing the earlier episode to be "unlearned" (McCloskey \& Cohen, 1989; Ratcliff, 1990). The fact that interference occurs does not pose a problem for the distributed models, but the fact that it occurs so quickly is a problem. Models in which episodes are represented separately (e.g., Logan, 1988) may have more success, but they will need to specify how an appropriate episode is located amongst the requisite huge number of episodes.

In summary, the evidence suggests that there are two kinds of repetition priming effects with differing lifespans. The short-term effect found in the masked priming paradigm is consistent with the idea that abstract lexical representations remain in a state of heightened accessibility for a brief time, but the long-term effect found in other paradigms seems to require a different kind of explanation, thereby ruling out the pure abstractionist approach. The obvious solution is to attribute long-lived priming (and perhaps short-lived priming as well) to episodic representations. As successful alternatives to the pure abstractionist approach are developed, they will need to address additional issues raised by the use of episodes. These issues include specifying how different tasks produce varying rates of forgetting for the same episodes, specifying how an appropriate episode is retrieved from among a very large number of episodes, and, in distributed models, solving the catastrophic interference problem (see Lewandowsky, 1991).

\section{The Influence of Details of Prior Occurrences}

When seeking to determine whether a task taps general or specific information, the following logic is often used: If the task relies on generalizations, then performance should not be affected when the stimuli vary in the aspects that have been generalized over. On the other hand, if the task relies on specific instances (i.e., exemplars or episodes), such variations should make a difference. For example, Brooks (1978) and Medin (e.g., Medin et al., 1982; Medin \& Schaffer, 1978) have shown that classification performance is influenced by the similarity of the test stimuli to individual exemplars seen during learning, and Ross (1987) has demonstrated that subjects are better able to use a provided formula to solve a word problem if the current problem has the same story line and object correspondences as an earlier problem that was solved using the same formula. This logic has also been used to ascertain whether word identification occurs through the use of general or specific information.

Thus, theories in which repetition priming is mediated by episodes predict significantly greater facilitation when the details of a prior occurrence are repeated, whereas theories in which priming is mediated by abstract representations predict a null result. Episodic theorists therefore have an advantage over abstractionists, because findings that conform to their competitors' predictions can be blamed on lack of sensitivity or power. 
This is unavoidable. However, it is worth noting whether the nonsignificant effects show a consistent pattern. That is, if repeating the original details truly has no impact on performance, then small, nonsignificant differences in favor of changed details should occur about as often as small, nonsignificant differences in favor of repeated details. On the other hand, if lack of sensitivity or power is preventing the detection of a genuine effect, then nonsignificant differences in favor of repeated details should dominate.

\section{Surface Form}

In visual word identification studies, variations in surface features, such as type case, type font, handwriting, and type orientation, have been employed to detect the use of episodes; in auditory studies, the speaker's voice has been varied. Nearly all of these experiments have measured long-term repetition priming. If word identification involves the use of specific episodes, then greater facilitation should be found when the surface features present at the item's first occurrence are repeated on its second occurrence; if abstract representations are involved, then the same amount of facilitation should occur regardless of whether surface features are repeated.

Many repetition priming experiments have varied language (e.g., Spanish vs. English), format (pictures vs. words), modality (e.g., visual vs. auditory), and wording (verbatim repetitions vs. paraphrases). However, these studies do not bear directly on the issue at hand, because abstractionists (e.g., Morton, 1979) have contended that separate representations are needed for different languages, for pictures and words, and for spoken and written words. Similar arguments have been made for such languages as Serbo-Croatian that can be written in two alphabets. For example, Lukatela, Turvey, Feldman, Carello, and Katz (1989) have proposed an abstractionist model in which separate letter units are used to identify Serbo-Croatian words written in Roman script and Cyrillic script. Moreover, because paraphrases and verbatim repetitions of text contain different words, both abstraction-based and episode-based theories of word identification would predict an advantage for verbatim repetitions. Therefore, the present review is limited to those studies that have manipulated the perceptual characteristics of single-modality stimuli from a single language with a single alphabet. Unless otherwise stated, all studies examined long-term repetition primingpriming that lasts for more than just a few seconds.

Geometrically transformed typography. One of the earliest proposals that highly specific episodic representations might be used in reading came from Kolers and Ostry (1974). In their experiments, subjects read aloud sentences that were either normally oriented or inverted (rotated $180^{\circ}$ on the $x$-axis; see Figure 1). After retention intervals ranging from $3 \mathrm{~min}$ to 32 days, they were given the previously seen sentences along with new sentences and were asked to read the sentences aloud before making a recognition judgment. Half of the old sentences were printed in their original orientation, and half were printed in the alternative orientation. The data most relevant for the present purposes are the rereading times for old sentences that were inverted at test; the rereading times for sentences that were normally oriented at test varied little and were not analyzed. At the three shortest delays ( $3 \mathrm{~min}, 1$ day, and 2 days), sentences that were inverted on both occasions were reread significantly faster than were sentences that were originally seen in normal orientation. These results led Kolers and Ostry to suggest that a record of the specific pattern-analyzing operations used to read a sentence is retrieved and used when the sentence is repeated. Consistent with this hypothesis, three experiments reported by Kolers (1975) also found greater savings for sentences that were inverted at both readings. Similarly, Masson (1984) found an advantage for mirror-image sentences (see Figure 1) that had originally appeared in mirror-image type over sentences that had originally appeared in normally oriented type. More recently, Craik and Gemar (as cited in Craik, 1991) also obtained results that favor the use of episodes.

Other findings, however, suggest that abstract representations mediate priming. Horton (1985) presented sentences in inverted or mirror-image type and varied whether they were repeated in the same transformed typography or in the other transformed typography. Contrary to the episodic view, none of the four experiments yielded a statistically reliable advantage for sentences repeated in their original transformed typography over those repeated in a different typography. Similarly, Tardif and Craik (1989) found that old passages that appeared in their original typographies were not reread significantly faster than were old passages that appeared in a different old typography. Furthermore, a second experiment found that although old passages were read faster if presented in their original typography, new passages were also read faster if presented in the old typography, and the size of the effect was the same for old and new passages. That is, the benefit of using the typography that had been seen in the study phase was the same for old and new passages, indicating that subjects

Normal geometrically transformed text

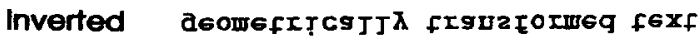

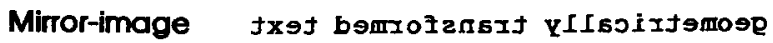

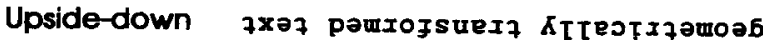

Backwards p9omeJYiosIIY JIEnzłorm9b J9XJ

Spelled yllacirtemoeg demrofsnart txet backwards

Figure 1. Examples of geometrically transformed text. 
had acquired some general skills needed to read the old typography.

Abstractionist accounts also gain support from the findings of Graf and Ryan (1990), who used the perceptual identification task rather than the rereading task. In Experiment 1 , subjects saw words printed in normal or upside-down type (see Figure 1), then attempted to identify old and new words in normal or upside-down type. The same-type conditions showed slightly more priming than did the different-type conditions, but the differences were not statistically reliable.

Some studies have not produced clear support for either view. For example, Graf and Levy (1984) found that inverted passages were reread faster if they had also been inverted on the first reading than if they had been normally oriented on the first reading, but only if three other passages intervened between the first and second readings. Later, Graf and Ryan (1990) obtained a reliable same-type advantage for backwards type (see Figure 1) but not for upside-down type.

Thus, transformed-text research has yielded what appears to be a mass of conflicting evidence. Fortunately, the conflict can be resolved by taking into account the fact that skill at reading one transformed typography transfers in varying degrees to the reading of other transformed typographies. After training subjects to read a particular typography, Kolers and Perkins (1975) gave them new passages in seven transformed typographies, including the one on which they had been trained. The amount of transfer between typographies relative to the amount of transfer within a typography was computed to obtain a measure of training potency. ${ }^{3}$

Interestingly, they found that transfer between two typographies was frequently asymmetric. For example, subjects trained on inverted type showed $95 \%$ transfer to new passages in mirror-image type, but subjects trained on mirror-image type showed only $28 \%$ transfer to new passages in inverted type. For the present debate, the crucial point is that the size of a same-font advantage is necessarily constrained by the amount of transfer from one typography to another. Therefore, if the typographies used in a particular experiment have high training potencies in one or both directions, it will be difficult to detect a same-font advantage.

High training potencies may have affected the outcomes of the studies that appeared to support the use of abstract representations. For example, a high degree of transfer from inverted to mirror-image type may have made it more difficult for Horton (1985) to detect an advantage for text presented twice in mirror-image type. On the other hand, because training on mirror-image type does not transfer well to inverted type, it should have been relatively easy to find an advantage for text presented twice in inverted type. Consistent with this argument, the effect of repeating the original typography appears to be larger for inverted sentences in three of Horton's four experiments. The training-potency hypothesis may also explain why Tardif and Craik (1989) found no same-font advantage and why Graf and Ryan (1990) obtained it for one font but not another. ${ }^{4}$

Recognizing that high training potencies could be a problem, Craik and Gemar (cited in Craik, 1991) chose typographies that had shown only $44 \%$ and $52 \%$ transfer to each other in the Kolers and Perkins (1975) study. In the first session, subjects read paragraphs in each of the transformed typographies. A week later, they returned and read both old and new paragraphs. As predicted by episodic accounts, old paragraphs repeated in their original typography were reread significantly faster than were those repeated in a different old typography. Craik and Gemar therefore concluded that reading involves the use of records of specific pattern-analyzing operations, just as Kolers (1975; Kolers \& Ostry, 1974) originally suggested.

Thus, although the results of the transformed typography experiments have been somewhat mixed, on balance they favor the view that repetition priming is mediated by specific episodes. It is worth pointing out that, in most of the experiments in which the key effect was not statistically reliable, there was a small difference in the direction predicted by the episodic view. Moreover, in some studies, substantial cross-typography transfer may have hindered the detection of a same-typography advantage.

Alternating type case. Rather than displaying all of a word's letters in one case, Brooks (1978) alternated cases within a word (e.g., LiNdA). Subjects searched through word lists to determine the number of first names or place names, and they were trained until they searched alternating-case lists as rapidly as they searched lowercase lists. Then, the subjects were given additional lists that contained the same words as the lists they had seen before but were printed in the complementary case pattern (e.g., IInDa). Changing the case pattern caused the reappearance of the initial advantage for lists printed entirely in lowercase type, suggesting that transfer was mediated by memory for specific visual patterns. Unfortunately, Brooks did not test a condition in which the same case pattern was repeated; this condition would have been useful for comparison purposes.

Masson (1986, Experiment 2), however, did include a same-case condition and found support for the episodic view. In addition to varying case pattern, Masson also reversed each letter (preserving the order of the letters within a word). At test, word triplets repeated in their original case pattern were reread faster than were triplets repeated in the complementary pattern. This effect was replicated in a third experiment. Thus, the results of the alternating-case experiments indicate that episodic representations mediate repetition priming.

Carr, Brown, and Charalambous (1989) argued that because text printed in transformed type or alternating cases is rarely encountered in "real life," experiments that employ these manipulations may not tell us much about how people normally read. In contrast, variations in type font, handwriting, and nonalternating type case 
are experienced daily and, hence, should not demand unusual processing. Experiments in which these more commonplace variations were used will be reviewed next. The predictions are the same as before: If abstract representations are used to identify words, changes in surface form should have no effect; if episodes are used, there should be more repetition priming when surface form is held constant. However, because the manipulations are less drastic than before, the key effect (if present) is likely to be even smaller and harder to detect.

Nonalternating type case. A number of researchers have varied whether words appear in uppercase letters or in lowercase letters at study and at test. An early series of lexical decision experiments conducted by Scarborough et al. (1977) produced mixed results for long-term repetition priming. Although they found no effect of case change in two of their experiments, another revealed a small advantage for the same-case condition. Scarborough et al. (1977) concluded that case change has "a very weak effect at best compared with the repetition effect itself" (p. 9). Nevertheless, they also commented that their findings could be explained by either the logogen model or a model in which multiple representations of words are stored.

Feustel, Shiffrin, and Salasoo (1983) used two other tasks in addition to perceptual identification and found no reliable effects of case change on long-term priming. (The task that Feustel et al. referred to as discrete threshold identification is the same as the traditional perceptual identification task.) In the continuous threshold identification (CTI) task, target-mask sequences were repeated in rapid succession, with the target duration becoming increasingly longer and the mask duration becoming increasingly shorter. When the display terminated, the subject attempted to identify the word. The continuous threshold latency identification (CTLI) task resembled the CTI task except that the subject terminated the display as soon as he or she could identify the word, and the primary dependent measure was RT rather than proportion correct. In an experiment that employed the perceptual identification and CTI tasks, Feustel et al. found only a slight, nonsignificant decrease in performance when type case was shifted between the third and fourth presentations. ${ }^{5}$ A similar outcome was obtained in an experiment that used the CTLI task and included a control condition in which words were repeated in the same case on all four presentations. These results are consistent with the use of abstract representations; nevertheless, because both words and nonwords showed priming, Feustel et al. concluded that episodic representations must play a role.

Other perceptual identification experiments have yielded mixed results. Jacoby and Witherspoon (1982) and Jacoby and Hayman (1987) found greater long-term repetition priming for words studied and tested in lowercase letters than for words studied in uppercase and tested in lowercase letters, but Levy and Kirsner (1989) did not. Jacoby and Hayman also tested words in uppercase letters and found no effect of case change. Simi- larly, no case effect occurred in Levy and Kirsner's second and third experiments, which used reading time as the dependent measure. These results support the claim that abstract representations mediate priming. (Nevertheless, Levy and Kirsner opted for an episodic view because of an effect of encoding context obtained in the first experiment; this finding is discussed in the Episodic Context section.)

Using a different task, Woltz (1990) did find an effect of case on long-term priming. In his experiment, subjects judged whether a pair of words were alike or different in meaning. For example, a positive response would be made to moist damp and a negative response would be made to moist blue. Although case did not affect accuracy, subjects responded faster to pairs repeated in their original case than to pairs whose case was changed.

Finally, masked form-priming. experiments consistently show short-term repetition priming despite the fact that the prime and target are presented in different cases (Forster \& Davis, 1984; Humphreys et al., 1988; Humphreys et al., 1987; Rajaram \& Neely, 1992). Moreover, Humphreys et al. (1988) found no correlation between the magnitude of short- or long-term priming and the amount of visual feature overlap between uppercase and lowercase items. Apparently, no one has directly compared changed-case items to same-case items in this paradigm to determine whether same-case items show more priming.

In summary, as predicted by the abstractionist approach, many of the experiments in which type case has been manipulated found no reliable effect of case change on long-term repetition priming. However, in nearly all of these experiments, there was a slight advantage for items repeated in the same case. The crucial comparison between same-case and different-case items has not been made in the short-term masked form-priming paradigm. Thus, the results of the type case experiments do not provide unequivocal support for either view.

Handwriting. Several experiments have varied whether words are typed or handwritten at study, with typed text used at test. Consistent with an abstractionist account, Clarke and Morton (1983) found no difference between the tachistoscopic thresholds obtained for typed words that had been studied in typed form and for typed words that had been studied in handwritten form.

Likewise, Levy and Kirsner (1989) found essentially the same amount of perceptual identification priming for words studied in handwritten form and tested in lowercase elite type as for words that appeared in lowercase elite type on both occasions. Similar results were obtained when subjects' rereading times for typed passages were measured: Although there were small differences in the direction predicted by episodic theories, they were not statistically reliable.

Using reading time as the dependent measure, Carr et al. (1989) also varied whether a passage appeared in type or handwriting on its first and second readings. In addition, they varied whether the passages were coherent or scrambled. After consistently failing to find a 
same-form advantage, Carr et al. concluded that abstract lexical representations are used for reading. However, a subsequent experiment using the naming and lexical decision tasks led Brown and Carr 1993; Carr \& Brown, 1990) to reject a pure abstractionist view. Words that were handwritten on both presentations showed more repetition priming than did words that were originally typed and were later handwritten; there was no effect of surface form for words that were typed on their second presentation. To explain these results, Brown and Carr proposed that specific occurrences of a word are retrieved if it appears in an unusual font or handwriting, but a visual prototype is activated if the word appears in a familiar font or handwriting. This hybrid account will be discussed in more detail later.

Using a "name and then decide" task, Manso de $\mathrm{Zu}$ niga, Humphreys, and Evett (1991) obtained similar results. Two items were sequentially presented on each trial. Subjects pronounced the first item, which was always a word, and made a lexical decision to the second item. The critical words were always pronounced on their initial presentation. On a word's second presentation, it appeared as a lexical decision item either in the same trial as the initial presentation (immediate condition) or after 15 intervening items (lagged condition). There was a same-handwriting advantage in the immediate condition, but there was no effect of repeating surface form in the lagged condition.

In summary, when words are typed on their second occurrence, it appears not to matter whether they were handwritten or typed on their first occurrence. Experiments in which words were handwritten at test have obtained mixed results. On balance, the results of the handwriting experiments are more consistent with the claim that abstract lexical representations are used to identify words.

Type font. Levy (1983) gave subjects error-free passages printed in elite or script type. After each passage had been read four times, the subjects were asked to proofread error-filled versions printed in elite type. As predicted by the episodic approach, subjects who had originally read the passages in elite type detected more errors than did subjects who had originally read the passages in script type.

In contrast, Graf and Levy (1984) found no effect of type font on rereading time. Inverted passages repeated in their original font were reread slightly faster than were inverted passages repeated in a different font, but the effect was not reliable. Similarly, Levy, Newell, Snyder, and Timmins (1986) found no effect of font on proofreading time or accuracy. In the same-font condition, subjects proofread a passage four times in a row and the passage always appeared in the same font. In the differentfont condition, the passage appeared in a different font for each presentation. As predicted by the abstractionist view, the same- and different-font passages were proofread at the same speed and with the same accuracy. Likewise, Levy and Kirsner (1989) found no effect of type font on rereading times for text passages. Subjects in their second experiment initially read passages in lower- case elite or script type, then reread them in lowercase elite type. The amount of priming in the lowercase elite and script conditions was nearly identical.

Jacoby and Hayman (1987) obtained mixed results when they simultaneously varied case and font. In this experiment, priming was greater for low-frequency words studied in the standard lowercase font used at test than for low-frequency words studied in a large, degraded, uppercase font. There was no effect of font for high-frequency words, perhaps because the amount of priming for these words was relatively small.

Clearer evidence for the use of episodes was obtained in an unpublished experiment conducted by Standen, Kirsner, and Dunn (described in Kirsner, Dunn, \& Standen, 1987). Subjects saw the words first in a lexical decision task and again in a perceptual identification task. Several type fonts that varied in their similarity to each other were used. The results showed that transfer increased with the similarity of the fonts used for the first and second presentations.

Graf and Ryan (1990, Experiment 3) used two unfamiliar fonts, Applesoft Shadow and Pudgy, and asked subjects to rate the readability or pleasantness of the study words. On a later perceptual identification test, the words appeared in their original font or in a different font. Consistent with the episodic view, subjects who had rated readability showed more priming for words that were repeated in their original font. However, this pattern of results did not occur in the group that had rated pleasantness at study. Graf and Ryan suggested that the readability group encoded more information about the perceptual details of the words at study, whereas the pleasantness group encoded more information about the meanings of the words. Because the memory representations of the readability subjects emphasized perceptual information, they showed a same-font advantage; because the memory representations of the pleasantness group emphasized a different kind of information, they could not show as much perceptual specificity. Clearly, Graf and Ryan interpreted their findings as evidence that episodes are used in reading.

Jacoby, Levy, and Steinbach (1992) also found an advantage for items repeated in their original font. Unlike Graf and Ryan (1990), however, Jacoby et al.'s results suggest that the same-font effect is more likely to occur when subjects process text for its meaning. In Experiment 1 , questions were displayed in elite type on a computer screen, typed in a script font on cards, or presented auditorily on a tape recorder. Half of the subjects read aloud the visually presented questions and repeated back the taped questions; the other half read or listened silently and answered the question. (An example question is, What bird looks dressed in a tuxedo?) In the second phase of the experiment, the questions always appeared in elite type on the computer screen, and subjects either reread the questions aloud or reread the questions silently and reanswered them aloud. In the reading-aloud condition, the standard rereading time measure was used. In the question-answering condition, the experi- 
menters recorded the time that elapsed between the appearance of the question on the screen and the initiation of the subject's answer. Reading-aloud subjects showed the same amount of repetition priming for all repeated questions, regardless of how the questions were originally presented. In contrast, the question-answering subjects showed more repetition priming for sentences originally presented in elite type than for sentences first presented in another form. The question-answering results were replicated in subsequent experiments that varied the delay between study and test (Experiment 2) and the proportion of overlap between the study and test lists (Experiment 3). Because delay and overlap had no effect on the amount of repetition priming that occurred, Jacoby et al. concluded that the key effect was not due to the intentional use of memory for previously presented items. Instead, they proposed that changes in surface form are more likely to influence performance when text is processed for its meaning, so that word identification occurs automatically through the retrieval of similar prior episodes.

Both Graf and Ryan (1990) and Jacoby et al. (1992) found evidence favoring an episode-based approach. Nevertheless, their findings appear to be in conflict with respect to whether perceptual specificity is more or less likely to be observed when subjects process text for its meaning. On one hand, Graf and Ryan's results suggest that variations in surface form have a greater impact if perceptual processing is emphasized; on the other hand, Jacoby et al.'s results suggest that such variations have a greater impact if processing of meaning is emphasized. How can these conflicting findings be explained?

A comparison of the methodologies employed by Graf and Ryan (1990) and by Jacoby et al. (1992) reveals a number of differences. First, Graf and Ryan used individual words in their experiments, whereas Jacoby et al. used sentences (mostly in question form). Second, Graf and Ryan manipulated study processing by having subjects rate words for readability or for pleasantness; Jacoby et al. manipulated study processing by having subjects read the questions aloud or read them silently and answer them aloud. Third, Graf and Ryan used the perceptual identification task, but Jacoby et al. used rereading time and reanswering time. Fourth, Graf and Ryan's subjects never performed the same task with the items at study and at test, whereas Jacoby et al.'s subjects always performed the same task on both occasions. Finally, as Jacoby et al. acknowledged, their reanswering time measure included the time needed to find an answer, not just the time needed to read the question. Further research is needed to determine which (if any) of these methodological differences is responsible for the conflicting results.

Levy, DiPersio, and Hollingshead (1992) reported several experiments in which changes in type font influenced proofreading performance. In their first experiment, subjects proofread a passage three times in a row (with different misspellings each time). Then, on the fourth trial, the experimenters changed the font in which the passage was typed (typescript condition), inserted additional spaces between some of the words (spacing condition), or repeated the passage in the same form (constant condition). As predicted by the episodic approach, proofreading times for the fourth presentation were significantly slower in the typescript and spacing conditions than in the constant condition, and accuracy also declined in the typescript condition. The effect on proofreading time was replicated in a second experiment in which the type font was changed for only 10 of the 350 words in the passage. Moreover, Levy et al. also showed that there was no difference in proofreading time for the constant and changed passages if subjects were proofreading them for the first time. This finding is crucial, because it shows that the slowdown was not due to the use of two different fonts within a single passage; instead, it was due to the discrepancy between the visual appearance of the current version of the passage and the visual information represented in memory.

In another experiment, Levy et al. (1992) used a clever technique to pinpoint the location of the slowdown. The procedure was the same as that used before, except that the errors were strategically placed and the subjects used a special pen to mark the errors that they detected while proofreading. Each time an error was marked, the pen signaled a computer to record the time that had elapsed since the previous mark, thus creating a series of intervals containing approximately the same number of words. On the final presentation of the passage, one word in the middle of an interval appeared in a different font. Changing the font of a single word slowed proofreading times both for the interval containing the critical word and for the following interval. This finding clearly shows that the slowdown in reading time occurs at the location of the font change.

Brown and Carr (1993) argued strongly against the pure episodic view because of their finding that when typical-looking type fonts are used in a naming or lexical decision task, changing fonts between the first and second presentations of a word has no effect. According to Brown and Carr, repeated exposure to words in ordinary type fonts results in the formation of visual prototypes. When a word appears in a typical font or handwriting, it is likely to retrieve the prototype rather than a record of a specific prior encounter with that word; hence, no same-font advantage will be observed. However, when a word appears in an unusual font or handwriting for which no visual prototypes exist, a specific episode containing a similar-looking stimulus will be retrieved.

Yet Brown and Carr's results are also consistent with a pure episodic model analogous to Medin and Schaffer's (1978) context model of categorization. That is, because one encounters many instances of words in typical-looking type, many highly similar episodes would be available to aid identification of a typical-looking word. In contrast, an unusual-looking handwritten word would normally bear only a modest resemblance to a few episodes; hence, repeating that word in its original sur- 
face form would considerably enhance its identification. Note that this pure episodic account is also consistent with the tendency to find larger surface form effects for low-frequency words than for high-frequency words (Jacoby \& Hayman, 1987).

In summary, consistent with the view that episodes are used to identify words, most type font experiments have found better performance when items were repeated in their original font. An important issue that remains unresolved concerns the conditions under which font effects are most likely to be found.

Auditory testing with voice variations. Morton (1979) conducted an auditory experiment analogous to the visual experiments discussed above. In the training phase, half of the subjects heard words spoken in a female voice and half heard them spoken in a male voice. At test, the words were spoken in a female voice against background noise and the subjects were asked to identify them. The dependent measure was proportion correct. Although the same-voice group showed slightly more priming than did the different-voice group, this difference was not statistically significant. A subsequent experiment by Jackson and Morton (1984) found no hint of voice-specific priming. Similarly, Schacter and Church (1992) found only a small, nonsignificant voice effect in two experiments that employed the auditory identification task. (Schacter and Church did obtain a same-voice advantage when they used a noise-free auditory stem completion task.)

However, subsequent research by Church and Schacter (1994) using a noise-free auditory identification task did find greater priming for words repeated in the same voice. Moreover, they also found effects of changing intonation and fundamental frequency within a voice. Changes in amplitude had no effect. Church and Schacter concluded that auditory repetition priming is produced by two presemantic subsystems, one that contains abstract phonological information and one that contains voice-specific acoustic information, such as fundamental frequency.

Summary of surface feature evidence. One hypothesis is that words are identified through the use of abstract representations that do not preserve the perceptual details of a particular occurrence of a word. Hence, variations in surface features, such as type case and type font, should not influence repetition priming. An alternative hypothesis is that words are identified by retrieving representations of specific prior occurrences. Because these specific representations include information about surface features, retrieval of a particular representation is more likely if the surface feature information that it contains matches that of the current stimulus. Therefore, the episodic approach predicts more repetition priming when surface features are kept the same from one occurrence to the next.

The effect of surface features on short-term repetition priming remains to be explored, but the effect on longterm priming is fairly clear: Consistent with the use of episodes, most experiments in which surface features were varied have found more long-term priming when the same surface features were present at study and test. The studies that did not yield a statistically reliable effect frequently found a small same-form advantage.

\section{Episodic Context}

A number of experiments have investigated the effect of changes in episodic context on the magnitude of longterm repetition priming. For example, some researchers have varied whether words that were paired at study are tested with their original pairmate or with a different word. In accordance with the encoding specificity principle (Tulving \& Thomson, 1973), episodic accounts predict that priming will be greater when the context present at study is reinstated at test because the reinstated context provides a more effective retrieval cue for the study episode. Presumably, any aspect of the reinstated context could trigger retrieval of the episode. That is, retrieval could occur because of a match between the perceptual characteristics of the test context and those of the study episode, or it could occur because of a match between the semantic processing induced by the test context and that performed during the study episode. Abstractionist accounts, on the other hand, predict no effect of the match between study and test contexts. (I do not mean to imply that abstractionist theories predict no effect of episodic context on any task, only that they predict no effect on word identification tasks. Episodic context effects on explicit memory performance would be attributed to the use of representations other than abstract lexical representations.)

Effect of encoding context on targets tested in pairs. After Tulving (1972) proposed the semantic/ episodic distinction, several researchers sought to test it by determining whether a word's context at study influenced later performance on that word in a semantic task: Subjects in these experiments studied pairs of words, then performed a lexical decision task that included the studied words. The critical manipulation concerned whether a studied target was again paired with its original context word (intact condition) or was paired with a different context word (broken condition). It was hypothesized that if semantic memory and episodic memory were functionally distinct, the match between context at study and context at test should not influence lexical decision performance. That is, there should be no pair-specific priming for lexical decisions.

These lexical decision experiments are relevant to the episodic/abstractionist debate because the episodebased view predicts more repetition priming for intact pairs than for broken pairs, whereas the abstractionbased view predicts no difference. In fact, more recent experiments involving repeated prime-target pairs have focused on the episodic/abstractionist debate rather than on the semantic/episodic debate. Unfortunately, the results have been far from clear: Although some experiments (Durgunoglu \& Neely, 1987; Goshen-Gottstein \& Moscovitch, in press; Masson \& Freedman, 1990; McKoon \& Ratcliff, 1979, 1986) have found an advan- 
tage for intact pairs, most others have not (Carroll \& Kirsner, 1982; Durgunoglu \& Neely, 1987; Neely \& Durgunoglu, 1985; Smith, MacLeod, Bain, \& Hoppe, 1989). Furthermore, several factors make it difficult to interpret the findings from these studies.

First, because so many variables must be counterbalanced, researchers have been forced to either tolerate confounds or have very few items per condition. Besides varying whether pairs are intact or broken, researchers must balance the lexical status of the targets, the study status of the targets, the study status of the primes, the semantic relatedness of the prime-target pairs, the prime-target stimulus onset asynchrony (SOA), and the number of SOAs per subject. Confounds have been present in most experiments. For example, in several of McKoon and Ratcliff's $(1979,1986)$ experiments, and in those of Smith et al. (1989) and GoshenGottstein and Moscovitch (in press), no nonwords appeared in the study list. Consequently, lexical decisions could be based partly on knowledge of a test item's study status. As another example, in Neely and Durgunoglu's (1985) first experiment, the lexical status of a prime's target in the study list predicted the lexical status of the prime's target in the test list. Neely and Durgunoglu corrected this problem in their second experiment, but, in doing so, were forced to change other aspects of their design.

Of course, adding conditions in order to avoid a confound usually reduces the number of items that serve in each condition. Not only does this increase the variability in the data, but it may also influence how subjects approach the task. Specifically, if intact prime-target pairs comprise only a small proportion of the test trials, or if studied primes tend not to be followed by their original targets, then it is not to the subjects' advantage to expect intact pairs. In most experiments, intact pairs have made up no more than $10 \%$ of the test pairs (e.g., $8.3 \%$ in Durgunoglu \& Neely, $1987 ; 8.3 \%$ in Neely \& Durgunoğlu, $1985 ; 10.0 \%$ in Smith et al., 1989). Moreover, the probability of a studied target, given the presentation of its original prime, has also tended to be low (e.g., .20 in Durgunoglu \& Neely, 1987; 33 and .20 in Neely \& Durgunoglu, 1985; .20 in Smith et al., 1989). Thus, it is possible that failures to find a pair-specific priming effect are due, at least in part, to the relative rarity of intact pairs in the test lists.

There are several cases in which pair-specific priming occurred despite a small proportion of intact pairs, but these experiments suffered from confounds. Although McKoon and Ratcliff (1986) reported reliable pairspecific priming when the probability of an intact pair was only 1 in $24(4.2 \%)$, study status was confounded with lexical status in that experiment. Similarly, GoshenGottstein and Moscovitch (in press), who presented the prime and target simultaneously, found pair-specific priming when $16.7 \%$ of the pairs were intact, but study status was again confounded with lexical status. Using homographs as targets, Masson and Freedman (1990) found a reliable RT advantage for repeated prime-target pairs over pairs in which the prime was new but biased the same meaning; repeated prime-target pairs comprised fewer than $6 \%$ of the trials. However, studied primes were always followed by their original targets, so that subjects could have used those primes as retrieval cues for the targets. ${ }^{6}$

Another factor that complicates interpretation of the lexical decision data is that the standard repetition priming and semantic priming effects were not obtained in some of the experiments. For example, in Neely and Durgunoglu's (1985) first experiment, the mean RTs for studied words preceded by a neutral prime were slightly longer than the mean RTs for unstudied words preceded by a neutral prime. Moreover, as the authors themselves pointed out, no semantic priming was found in either of their experiments. In subsequent research, Durgunoglu and Neely (1987) obtained repetition priming effects ranging from 3 to $60 \mathrm{msec}$, but again found no evidence of semantic priming. (Neither Neely \& Durgunoglu, 1985, nor Durgunoglu \& Neely, 1987, performed any statistical tests to determine whether significant repetition priming had occurred.) The absence of these basic priming effects raises the possibility that some aspect of the procedure may have interfered with the processes that normally give rise to priming. On the other hand, Smith et al. (1989) failed to find pair-specific priming despite the presence of significant repetition priming.

Finally, another issue concerns what Smith et al. (1989) have called list-wide priming. Although Smith et al. found no pair-specific priming in their experiments, they did find that, at an SOA of $250 \mathrm{msec}$, responses to intact and broken pairs were faster than responses to targets preceded by unstudied primes. In other words, subjects responded faster to old targets if they were preceded by old primes, regardless of whether the prime and target had been studied together. This listwide priming effect, which disappeared when the SOA was lengthened to $1,000 \mathrm{msec}$, cannot be explained by abstractionist theories because they do not provide a way for the study status of one word to influence the identification of another word. In contrast, an episodic theory could account for list-wide priming if a studied prime causes the retrieval of other studied items in addition to the target with which it was originally studied. If the target happens to be among the retrieved items, it could be identified more rapidly. Nevertheless, the absence of pair-specific priming over and above this list-wide priming is problematic for episodic theories, because a studied prime should be more likely to retrieve its original target than any other studied targets.

For some of the experiments cited here, it is impossible to determine whether list-wide priming occurred, because not all of the necessary conditions were run. However, Carroll and Kirsner (1982) and Neely and Durgunoglu (1985) did include the key conditions. Although Carroll and Kirsner did not compare statistically the condition in which one member of a pair was old with the conditions in which both members were old, the means suggest that a small list-wide priming effect may 
have occurred. On the other hand, in Neely and Durgunoglu's experiments, responses to studied targets were 7-64 msec slower when they were preceded by studied primes than when they were preceded by unstudied primes. Thus, it is not clear whether the list-wide priming effect is a reliable phenomenon. If it is, it poses problems for both the pure abstractionist and the pure episodic approaches.

As in the experiments just described, Toth and Hunt (1990) varied whether the context word that preceded the target at test was the same as the one presented at study. However, Toth and Hunt also varied whether the target word was displayed at study (read targets) or had to be generated by the subject (generated targets). In addition, they used the perceptual identification task rather than the lexical decision task. Consistent with the episodic view, generated targets showed significantly more priming if the original context word was repeated than if a different context word appeared. A small, nonsignificant difference in the same direction was obtained for read targets.

Unfortunately, studied context words were always followed by their original targets, so that subjects could have used the studied context words as retrieval cues for their corresponding targets. To address this problem, Toth and Hunt (1990) ran another experiment that replaced the different-context condition with "catch" trials in which studied context words were followed by unstudied targets. Toth and Hunt reasoned that because generation influences cued recall, subjects who treat the identification task as a cued recall task should retrieve the original target more often for context words that had originally appeared in the generate condition than for those that had originally appeared in the read condition. Assuming that retrieving the original target interferes with identification of the current target on catch trials, interference should occur on catch trials in which the context word had appeared in the generate condition. In fact, catch trial performance was equivalent in the read and generate conditions, leading Toth and Hunt to conclude that their previous results could not be attributed to the use of a cued recall strategy. However, the generation effect for same-context targets was smaller in the catch-trial experiment and just missed statistical significance. Furthermore, Toth and Hunt's analysis of errors on catch trials revealed that generated targets were produced more frequently than read targets. Therefore, the results of this experiment do not clearly rule out a cuedrecall explanation.

Finally, Goshen-Gottstein and Moscovitch (in press) reported pair-specific priming when subjects were asked to judge whether the words in a pair were related in meaning. Responses to intact related pairs were faster than responses to recombined related pairs, but the reverse was true for unrelated pairs. That is, having studied two unrelated words together made it harder for subjects to reject them as unrelated. These results indicate that associating two words at study influenced how the words were processed in the relatedness judgment task.
Effect of encoding context on targets tested alone. Another set of studies has focused on how encoding context influences the processing of the target word, which is later tested alone. In most of these experiments, target words were originally presented alone or in the context of a related or unrelated word. ${ }^{7}$ Because the test involves the presentation of single words, episodic accounts predict more priming for targets that were originally read in isolation (same context) than for targets that were originally read in pairs (different context).

In a seminal paper, Jacoby (1983b) reported three experiments in which targets that were preceded at study by a string of Xs (e.g., xxxxxx followed by cold) showed more perceptual identification priming than did targets that were preceded at study by an antonym (e.g., hot followed by cold). Jacoby interpreted this finding as support for a processing-oriented episodic account of repetition priming. Similar results were reported by Masson and MacLeod (1992), whose subjects studied targets alone or with a modifier (e.g., saucer or flying saucer). As expected, targets studied in isolation showed more priming than did targets studied with a modifier.

In Jacoby's (1983b) fourth experiment, he included some study trials in which the context word was followed by an unrelated word rather than by an antonym. For example, when shown the context word hot, a subject would expect to see cold as the target, but down would be displayed instead. Targets originally seen in this incongruent-context condition were more likely to be identified than were targets in the no-context and congruent-context conditions. In other words, performance was actually better in a different-context condition than in the same-context condition - a result not readily explained by either a simple episodic view or a simple abstractionist view.

To account for this finding, Jacoby suggested that perceptual identification relies primarily on data-driven processing, and that the degree of repetition priming found in a particular encoding condition depends on the extent to which it promotes data-driven processing. By this account, subjects used the context words to predict the target words, so that less data-driven processing was needed to identify the targets on congruent trials. On nocontext trials, subjects would not expect a particular target, so identification would occur primarily through data-driven processing. On incongruent trials, subjects would attempt to predict the target, but their predictions would be incorrect; hence, even more data-driven processing would be required. Therefore, targets seen in the incongruent condition should show more repetition priming than should targets seen in the no-context condition, which in turn should show more priming than should targets seen in the congruent condition.

Jacoby's (1983b) explanation is clearly an episodic one because it claims that repetition priming is influenced by the way in which a word was processed on a particular occasion. It further suggests that the reinstatement of context involves more than just the repetition of context items; in addition, the processing of the 
items must be similar. Unfortunately, this revision of what is meant by reinstatement of context raises another problem: Without some independent means of determining what kind of processing is being done, the theory is not truly falsifiable. Furthermore, the priming advantage for targets encoded with unrelated context words apparently does not extend to the lexical decision task or the naming task (Durgunoglu, 1988).

Weldon (1991, Experiment 4) used yet another method of investigating the influence of context on perceptual identification priming. In her experiment, target words were always tested alone; what varied was whether the meaning of the target suggested by the context at study was the same as the meaning likely to be used at test. For example, the target word black could initially appear in blackbird (same meaning) or in blackmail (different meaning). Equal amounts of priming occurred in the same- and different-meaning conditions.

Although this result appears to be consistent with the pure abstractionist approach, Weldon (1991) proposed an episodic account within the transfer-appropriate processing framework outlined by Roediger, Weldon, and Challis (1989). According to this account, the perceptual identification task relies primarily on perceptual, rather than conceptual, processes. Hence, when a specific prior processing episode is retrieved for use in the perceptual identification task, only the perceptual aspects of that episode will influence performance. Still, abstractionists could argue that the lack of a same-meaning advantage supports their position.

Word triplets. Masson's (1986) subjects read triplets of words printed in mirror-image alternating case type. At test, the words appeared either in their original triplets or in new triplets formed by combining words that had originally appeared in different triplets. As predicted by the pure abstractionist view, the rearranged triplets were reread just as rapidly as the intact triplets. However, other results led Masson to prefer an episodic account. (See "Alternating type case" under the Surface Form section.)

The results of Whittlesea and Brooks's (1988) Experiment 7 clearly bolster the episodic approach. During the training phase, subjects were asked to copy from the computer screen a phrase or a word presented alone. The phrases were adjective-adjective-noun triplets (e.g., heavy steel box) and noun-verb-adverb triplets (e.g., rocks flew fast). At test, phrases and single words were displayed briefly before being masked, and subjects were asked to write down each phrase or word that they saw. A word that was originally seen in a phrase could appear in the same context, a new context (with two words not seen during training), a re-paired context (with two words from different previously seen phrases), or no context. A word that was originally seen with no context could appear at test with no context, a new context (with two words not seen during training), or a re-paired context (with two words from different previously seen phrases). The dependent measure was the proportion of target words correctly identified. As predicted by the episodic view, identification performance was best when the target item appeared in the same context at training and at test. Changing a target word's context made identification more difficult, especially if the context words had been seen with other targets during the training phase.

Interestingly, Whittlesea and Brooks's (1988) finding that identification was more accurate for new-context targets than for re-paired targets runs counter to Smith et al.'s (1989) list-wide priming effect. One possible reason for this discrepancy is that Whittlesea and Brooks's phrases formed a more cohesive unit than did Smith et al.'s word pairs. Another possibility is that when the mask prevented Whittlesea and Brooks's subjects from seeing the target word clearly, they used the context words to constrain their guessing. Such a strategy would hurt performance more in the re-paired condition than in the new-context condition, because when given studied context words, subjects would be likely to respond with the target that had originally appeared with those context words. When given new context words, subjects would have little reason to expect a particular studied target; hence, less inhibition would occur. On the other hand, in Smith et al.'s lexical decision experiments, presentation of a studied prime may have caused the rapid (within $250 \mathrm{msec}$ ) retrieval or activation of several studied words. If the retrieved set usually included both the original target and the current target, then list-wide priming would occur. Unstudied primes would tend not to retrieve list words, so lexical decisions to studied targets following unstudied primes would take longer. The question of whether a different studied context causes facilitation or inhibition relative to a new context deserves further investigation, because the results may constrain models of performance on various tasks.

Sentences. Lewandowsky, Kirsner, and Bainbridge (1989) asked subjects to perform two blocks of lexical decision trials, with some of the targets from the first block repeated in the second block. Each target was preceded by a sentence that served as a contextual frame for the target. In their first two experiments, the targets were homographs (e.g., bank) and the context sentence biased one of the homograph's meanings. At test, the context sentence could be the same as in the first block (same-context condition), a different sentence that biased the same meaning (different-context condition), or a different sentence that biased a different meaning (different-meaning condition). Filler trials were included so that previously seen context sentences were not always followed by previously seen targets. Consistent with the use of episodes, no significant repetition priming occurred in the different-meaning condition. More importantly, when the dominant meaning of a target was biased on its second presentation, subjects showed more priming for targets in the same-context condition than for targets in the different-context condition. On the other hand, the context effect was not reliable when the subordinate meaning was biased at test.

In a third experiment, Lewandowsky et al. (1989) used nonhomographs as targets and compared the effect 
of context on high- and low-frequency words. Highfrequency words showed significantly more repetition priming when the same context sentence was presented in both blocks than when different context sentences were presented, but this effect was not reliable for lowfrequency words. Thus, the results obtained with highand low-frequency nonhomographs mirrored those obtained with the dominant and subordinate meanings of homographs. Although Lewandowky et al.'s results could be construed as evidence for the use of episodes, the authors proposed an abstractionist account in which each sense of a word has its own lexical representation.

Additional support for the sense-specific account was obtained by Bainbridge, Lewandowsky, and Kirsner (1993). In their first experiment, subjects were asked to make lexical decisions about nonhomographic items presented as possible sentence completions. Some of the target words had only one or two senses, whereas others had three or more senses for a single meaning. Targets in the same-context condition were repeated with their original sentence frames; targets in the different-context condition were repeated with a new sentence frame that either biased the same sense (for few-sense words) or a different sense (for many-sense words). Bainbridge et al. found that changing the context reduced repetition priming only when it also changed the sense of the word. Similar results were obtained in two subsequent experiments in which the context sentence was always changed between presentations and what varied was whether the same sense was biased. The sense-specific activation theory can also account for Masson and MacLeod's (1992, Experiment 8) findings. Their subjects read single target words or target words embedded in sentences, then performed a perceptual identification task with single words. As predicted by the episodic view, targets read in isolation showed more priming than did targets read in sentences. Alternatively, Bainbridge et al. (1993) suggested that this pattern of results is due to the greater tendency for the same sense of a word to be activated if it is presented singly both at study and at test; embedding the target in a context at study may reduce priming if the sense biased by the context differs from that activated when the target is tested alone.

Text passages. Levy (1983) had subjects read errorfree passages four times, then asked them to proofread error-containing versions of the passages. For one group, the words in the passages were scrambled during the familiarization phase; for the other group, the words appeared in their original order. The effect of familiarization was assessed by comparing the proportion of errors detected in familiar and unfamiliar passages during the $1.5-\mathrm{min}$ proofreading period. Consistent with the abstractionist view, the familiarization effect was about the same in the normal and scrambled groups.

When subjects were allowed to proofread entire passages so that both proofreading time and accuracy could be measured, Levy and Begin (1984) again found no effect of scrambling on accuracy. However, they did find an effect on proofreading time. In Experiment 1, the pas- sages always appeared in normal form during the familiarization phase but could appear in either normal or scrambled form at test. Collapsing across easy and difficult passages, familiar passages tested in normal form showed reliable repetition priming, but familiar passages tested in scrambled form did not. In Experiment 2, passages could appear in scrambled form during familiarization as well as at test. As predicted by the episodic view, the familiarization effect was larger for passages repeated in their original form than for passages repeated in a different form.

Using a different type of manipulation, Levy and Kirsner (1989) also found an effect of context. In their first experiment, subjects studied single words or read those same words embedded in a text passage. On a later perceptual identification task with single words, subjects who had studied single words showed repetition priming, but subjects who had read text passages did not. This result led Levy and Kirsner to adopt an episodic account of repetition priming.

Like Levy (1983) and Levy and Begin (1984), Carr et al. (1989) manipulated context by presenting coherent or scrambled text. However, Carr et al. measured rereading time. In their first experiment, coherence on the initial reading was crossed with coherence on the second reading. Consistent with an abstractionist account, Carr et al.'s analyses revealed no effect of context match on reading times. Nevertheless, inspection of their Figure 1 (Carr et al., 1989, p. 768) suggests that when the second reading was scrambled, subjects who had originally read the text in scrambled form reread it faster (i.e., showed repetition priming), whereas subjects who had originally read the text in coherent form reread it more slowly.

Using a silent reading task, Levy and Burns (1990) varied the level at which texts were scrambled on their first and second readings. In Experiment 1, they scrambled the order of the paragraphs in a passage but left each paragraph and sentence intact; in Experiment 2, they scrambled the order of sentences in the passage but left the order of the words in each sentence intact; in Experiment 3 , they scrambled the order of the individual words. Scrambling the order of the paragraphs in a passage did not affect repetition priming. However, when the test passage was normal, subjects who had originally read it in normal form ( $\mathrm{N}-\mathrm{N}$ condition) reread it faster than did subjects who had originally read scrambled sentences or words (S-N condition). There was little or no difference between the conditions in which the passage was scrambled on its second presentation (S-S and N-S conditions). A fourth experiment that varied word order and required subjects to read aloud produced similar results. Two additional experiments by Levy, Masson, and Zoubek (1991) also yielded the same pattern.

The superiority of the N-N condition over the S-N condition is consistent with the use of specific episodes; yet the equivalence of the S-S and N-S conditions suggests the use of abstract lexical representations. Preferring an episodic account of repetition priming, Levy and her colleagues (Levy \& Burns, 1990; Levy et al., 1991) 
proposed that the S-S condition failed to outperform the $\mathrm{N}-\mathrm{S}$ condition because subjects read for comprehension, attempting to make sense of the scrambled text. By this account, subjects who had initially read the text in its normal form possessed a stable, coherent representation that later enabled them to interpret the scrambled text in a meaningful way. In contrast, subjects who had initially read the text in scrambled form were unable to form a stable representation that could be used to facilitate processing later on.

In fact, Whittlesea (1990) has argued that differences in the way coherent text and scrambled text are processed make the coherence manipulation inappropriate as a manipulation of context. According to Whittlesea, a more appropriate way to vary context is to use two different scrambled versions of the same text. Using this method, he found that subjects who read the same scrambled version of a passage twice showed significantly more repetition priming than did subjects who read two different scrambled versions. This result clearly supports the hypothesis that specific episodes are used in reading.

Whittlesea's (1990) point notwithstanding, Carlson, Alejano, and Carr (1991) employed the coherence manipulation and found evidence for the use of episodes. Besides varying whether passages were coherent or scrambled on their first and second readings, Carlson et al. also used an instructional manipulation to influence the linguistic level at which the passages were represented in memory. To encourage construction of textlevel representations, some subjects were told to read each passage with the goal of comprehending its overall meaning; to encourage construction of word-level representations, other subjects were told to keep track of each word in the passage as they read. Furthermore, the authors hypothesized that repetition priming-and, hence, an effect of context on priming-would occur only when the same level of representation could be used on both readings. More specifically,

\begin{abstract}
Under instructions to read for text-level meaning, repetition benefit should occur when the text for the second reading matches the text of the first reading in coherence because the text-level representation serves as the unit for repetition benefit, and that unit is being repeated. However, when the first and second readings mismatch in coherence, the text-level representation is not being repeated. Therefore, no benefit should be seen. In contrast, under instructions to read word by word, the representational unit that serves as the basis for repetition benefit is the word. Because repetition of this unit occurs regardless of whether the first and second readings match in coherence, benefit should be evident in both the matched and the mismatched conditions. (Carlson et al., 1991, pp. 926-927)
\end{abstract}

The results were essentially as predicted. When the test passage was scrambled, repetition priming always occurred, but both the text group and the word group showed more priming if the passage had originally been read in scrambled form. When the test passage was coherent, the text group showed priming only if the pas- sage had originally appeared in coherent form. The word group showed priming in both conditions, but there was a small advantage for passages originally read in coherent form. In other words, as predicted by the episodic approach, Carlson et al. (1991) obtained more priming when the words in a passage appeared in the same order on both the first and the second reading. Moreover, the effects of the instructional manipulation provide further support for the idea that context is determined by processing as well as by what items are present at study and test.

Test list. The context manipulation used by Jacoby (1983a) is very different from those described thus far. Using perceptual identification as the dependent measure, Jacoby varied the amount of overlap between the study and test lists. In one condition, $90 \%$ of the tested words had been studied, and subjects were told that some of the words from the study list were also on the test list. In the other condition, only $10 \%$ of the tested words had been studied, and subjects were told that the test list was a new list. The critical words were those that appeared in the test lists for both groups, so that what varied was the context in which those words appeared at test. Jacoby reasoned that the study and test contexts would be more similar in the $90 \%$ condition than in the $10 \%$ condition; hence, according to the episodic view, repetition priming should be greater in the $90 \%$ group. This prediction was confirmed.

As Jacoby (1983a) acknowledged, however, proportion overlap was confounded with test instructions in this experiment. Specifically, subjects in the $90 \%$ condition were informed that the study and test phases were related, whereas subjects in the $10 \%$ condition were led to believe that they were unrelated. Thus, it is possible that the change in instructions is responsible for the difference that was observed. Completely crossing instructions with overlap was not feasible because subjects in the $90 \%$ condition probably would have caught on to the fact that many of the test words came from the study list; however, it would have been useful to run a condition in which $10 \%$ of the test words had been studied and subjects were informed of the relation between the study and test phases.

Summary of episodic context evidence. Design problems make the results of some episodic context experiments difficult to interpret. In particular, many of the lexical decision experiments confounded the lexical status of a prime or target with the study status of the prime or target. In addition, the relative rarity of trials on which the original episodic context was preserved may have influenced how the subjects approached the task. Nevertheless, most of the methodologically sound experiments found more long-term repetition priming when the contextual information present at study was reinstated at test. Furthermore, the results of some studies suggest that it is also important that the same kind of processing be performed on both occasions. Clearly, these findings support the claim that episodic representations are involved in word identification. 
Still, abstractionists could account for most episodic context effects by positing separate representations, not just for different meanings of a homograph but also for different senses of one meaning of a word (Bainbridge et al., 1993; Lewandowsky et al., 1989). However, this modification leaves unresolved the problems of explaining the longevity and perceptual specificity of long-term repetition priming.

\section{Word-Pseudoword Differences}

Another line of evidence relevant to the abstractionstepisodic debate comes from repetition priming experiments in which nonwords were tested. In most cases, the nonwords were pseudowords-pronounceable letter strings formed by changing one letter of a real word. Due to the method of construction, most pseudowords have been consistent with the orthographic rules of the language. However, because they are novel, pseudowords presumably do not have abstract lexical representations-at least, not prior to the experiment. Consequently, unless a single exposure is sufficient to establish a lexical entry, the abstractionist view predicts that we should be able to find differences in repetition priming for words and pseudowords.

As explained earlier, words show two kinds of repetition effects: Short-term priming occurs within a trial when the prime and target cannot be distinguished as separate events, whereas long-term priming occurs across trials or within a trial when the prime and target can be distinguished. Long-term repetition priming for pseudowords has been obtained with the perceptual identification task (e.g., Feustel et al., 1983; Rueck1, 1990; Salasoo, Shiffrin, \& Feustel, 1985; Whitlow \& Cebollero, 1989), the naming task (Brown \& Carr, 1993), and other word identification tasks (Brown \& Carr, 1993; Feustel et al., 1983; W. A. Johnston, Dark, \& Jacoby, 1985). The lexical decision results have been mixed: Whereas some researchers have obtained facilitation for pseudowords (Besner \& Swan, 1982; Dannenbring \& Briand, 1982; den Heyer, 1986; Kirsner \& Smith, 1974; Logan, 1988, 1990), some have found no effect or slight inhibition (Brown \& Carr, 1993; Duchek \& Neely, 1989; Durgunoglu \& Neely, 1987; Forbach, Stanners, \& Hochhaus, 1974; McKoon \& Ratcliff, 1979; Neely \& Durgunoglu, 1985). However, as others (Duchek \& Neely, 1989; Feustel et al., 1983; McKoon \& Ratcliff, 1979) have pointed out, most of the experiments that have found facilitation used the lexical decision task for both presentations, so that subjects made negative responses on both occasions. In contrast, most of the experiments that found inhibition or no effect did not use the lexical decision task for the first presentation. Hence, subjects probably found it difficult to reject items that seemed somewhat familiar unless they had made the same response on the first presentation.

Although Sereno (1991) found significant masked repetition priming for unstudied pseudowords presented in a lexical decision task, Rajaram and Neely (1992) obtained it only for pseudowords that had appeared in an earlier study list. ${ }^{8}$ The masked priming experiments in which perceptual identification accuracy or naming time was measured did not include pseudowords. Thus, it is unclear whether short-term priming occurs for pseudowords, but long-term repetition priming certainly does.

Some investigators have proposed that pseudowords are pronounced by partially activating the lexical entries of the real words that they resemble (Glushko, 1979; Rosson, 1983, 1985). The obvious way to extend this proposal to repetition priming is to assume that the partially activated representations remain highly accessible for some time after a pseudoword is presented. As Rueckl (1990) pointed out, partially activated lexical representations should return to their resting levels sooner than fully activated lexical representations should. Consequently, pseudoword priming should not last as long as word priming. This prediction is supported by several lexical decision experiments that varied the lag between the first and second presentations of an item (Dannenbring \& Briand, 1982; Kirsner \& Smith, 1974; Scarborough et al., 1977, Experiments 1 and 4). On the other hand, Scarborough et al. (1977, Experiment 2) obtained the opposite result in another lexical decision experiment: Repetition priming for words decreased as lag increased, but repetition priming for pseudowords was unaffected. Because prior study can make it harder for subjects to reject pseudowords on the lexical decision task, it is not clear how the data from that task should be interpreted. Unfortunately, the results for other tasks have been no less confusing: Using the naming task, Scarborough et al. (1977, Experiment 3 ) found that lag affected the naming of pseudowords more than the naming of words, yet Feustel et al. (1983) and Salasoo et al. (1985) found no lag effects for words or pseudowords with either the perceptual identification task or the CTI task. Thus, the relative longevity of word and pseudoword priming remains an unresolved issue. Nevertheless, even if pseudoword priming were found to be less durable than word priming, advocates of the partial-activation view would still be faced with the inability of abstractionist accounts to explain long-term priming for words.

Other findings taken as support for a partial-activation account can also be explained by episodic theories. For example, the partial-activation view predicts that the presentation of pseudowords should prime the words that they resemble, a prediction that was confirmed by Rosson $(1983,1985)$. However, because the episodic approach holds that retrieval is similarity-based, it predicts that pseudowords should retrieve episodic representations of similarly spelled words.

A second prediction derived from the partial-activation view is that repetition priming should increase with the similarity of nonwords to words. Consistent with this prediction, Scarborough et al. (1977) found more lexical decision priming for pronounceable nonwords than for unpronounceable nonwords, and Bowers (1994) obtained the same results with the perceptual identification task. Likewise, using a task in which subjects judged 
whether a letter string could form a "good" English word, Dorfman (1994) found reliable repetition priming for pseudowords composed of English morphemes and syllables (e.g., genvive), but not for pseudowords that did not contain English morphemes or syllables. Again, the episodic approach predicts the same result: Because the retrieval of episodes is assumed to be similarity-based, nonwords that more closely resemble real words should show more priming.

Salasoo et al. (1985) acknowledged that episodes play a role in repetition priming, but argued that several of their findings could not be explained without also positing abstract lexical codes. First, Salasoo et al. found that identification performance was better for words, which presumably have lexical codes, than for pseudowords, which presumably do not have codes. Nevertheless, because pseudowords are not likely to have been encountered prior to the experiment, this difference could also be attributed to a lack of useful episodes containing pseudowords.

Second, both Feustel et al. (1983) and Salasoo et al. (1985) found that the superiority of new words over new pseudowords was greater in one of their identification tasks than it was in the other and attributed this difference to the presence of codes for words. The task showing the larger word advantage was the traditional perceptual identification task. In the CTI task, target-mask sequences were repeated in rapid succession, with the target duration becoming increasingly longer and the mask duration becoming increasingly shorter. When the display terminated, the subject attempted to identify the word. Feustel et al. suggested that the forgetting of perceptual features has a greater impact on perceptual identification performance than on CTI performance because the CTI task allows forgotten features to be recovered on the target's next exposure. They further suggested that the word-pseudoword difference is larger in the perceptual identification task because lexical codes are available to facilitate encoding and response processes for words but not for pseudowords. However, this finding is also consistent with a strategy explanation that does not assume the use of abstract lexical codes. In the perceptual identification task, the subject must respond on the basis of the information available from a single brief presentation. Hence, a reasonable strategy to use when only partial information is obtained would be to respond with an item that is consistent with the information. Obviously, this strategy leads to an advantage for words over pseudowords. In contrast, the CTI task allows the subjects to obtain more information about the target before responding; if one of the letters is unclear, it may become clearer on its next exposure. Thus, it would less often be necessary to use prior knowledge to generate educated guesses, and the word-pseudoword advantage would be reduced.

Third, because subjects performed equally well on old words, new words, and old pseudowords after a 1-year delay, Salasoo et al. (1985) concluded that lexical codes for the old pseudowords had developed when they were presented repeatedly in the original experimental sessions. Nevertheless, it is possible that specific episodes were being used, especially given that recognition memory for old words and pseudowords was still above chance. In fact, $d^{\prime}$ for pseudowords was a respectable 1.836 .

Fourth, Salasoo et al. (1985) argued that episodic models predict that a single repetition will benefit pseudowords more than words because initial performance on pseudowords is lower, yet they found equal benefits for words and pseudowords. However, as J. C. Johnston, van Santen, and Hale (1985) pointed out, the self-scoring procedure used by Salasoo et al. provided an additional presentation for each item: After the subject had responded, the correct word or pseudoword was displayed and the subject pressed a key to indicate whether his or her response was correct. The problem with this procedure is that on correct trials, the subjects saw the correct item twice (once for testing purposes and once for scoring purposes), but, on error trials, the subjects saw the correct item only once (for scoring purposes). Because initial performance is better for words than for pseudowords, more words than pseudowords would be seen twice. Thus, it could be that in Salasoo et al.'s experiment pseudowords did benefit more from a single prior exposure, but the additional exposure given to more of the words compensated for it. Thus, despite Salasoo et al.'s arguments to the contrary, lexical codes are not needed to explain their pseudoword data.

Whitlow (1990; Whitlow \& Cebollero, 1989) also argued that abstract representations are needed to explain differences in the effect of repetitions on words and pseudowords. Whitlow and Cebollero (1989) found that a single repetition benefited words more than pseudowords but that pseudowords benefited more from further repetitions. Whitlow (1990) subsequently reported that perceptual identification priming for words increased with additional repetitions if subjects were told to expect a recall test, but not if they were told to expect an unspecified memory test. In contrast, the effect of additional repetitions on priming for pseudowords did not vary with instructions. Whitlow hypothesized that subjects typically use codified representations to identify words but will shift to episodic representations if they expect a later episodic memory test. Because pseudowords do not have codified representations, episodic representations are used to identify them regardless of what kind of test is expected.

On the other hand, Rueckl (1990) obtained more priming for words presented three times at study than for words presented only once but did not obtain the same effect for pseudowords. These results appear to conflict with Whitlow's (1990; Whitlow \& Cebollero, 1989). However, an examination of the figures from Whitlow (1990) suggests that word priming increased with a second and third repetition, then leveled off. That is, comparison of the data from the conditions common to both studies indicates more priming for thrice-repeated words than for once-repeated words. Unfortunately, it is not so 
obvious how to resolve the conflicting results for pseudowords: Whitlow and Cebollero found that multiple repetitions benefited pseudowords more than words, whereas Rueckl found the opposite.

Logan also investigated the effects of multiple repetitions on words and pseudowords, but, in his experiments, the items were always seen in either a lexical decision task or a pronunciation judgment task. That is, there was no "study list." These experiments consistently found more priming for pseudowords than for words when the training session data were collapsed over number of repetitions (Grant \& Logan, 1993; Logan, 1988, 1990). Also, additional repetitions continued to produce improvements in performance on both words and pseudowords before asymptoting at 8-12 presentations. Clearly, the effects of multiple repetitions on word and pseudoword identification require further investigation.

Moreover, some word-pseudoword differences may be related to the fact that subjects know meanings for words but not for pseudowords. Using the ReicherWheeler letter identification task, Whittlesea and Cantwell (1987) demonstrated that repetition priming is enhanced if subjects learn definitions for pseudowords. Taking a pure episodic approach, Whittlesea and Cantwell suggested that learning a definition led subjects to process a pseudoword in a more integrated fashion, resulting in an episodic representation that was more effective as an aid to identification. In addition, Rueckl and Olds (1993) found that thrice-presented pseudowords showed more perceptual identification priming than did once-presented pseudowords if the subjects had learned definitions for the pseudowords. To explain their findings, Rueckl and Olds proposed a weakly episodic connectionist model in which connections between orthographic and semantic units facilitate the identification of meaningful pseudowords.

Consistent with this model, subsequent research by Rueckl and Dror (1994) revealed that pseudowords were easier to identify if their spellings were systematically related to their meanings (e.g., durch = "dog" and hurch = "cat"; same word ending used for members of the mammal category) than if their spellings and meanings were unrelated (e.g., durch = "dog" and hurch = "shirt"; same word ending used for members of different categories). The ability of connectionist models to capitalize on such correlations deserves further exploration. For example, orthographic-semantic connections may have contributed to Dorfman's (1994) finding that repetition priming occurs only for pseudowords constructed from letter combinations that serve as morphemes and syllables in English words.

\section{Summary of Pseudoword Evidence}

It has been argued that abstract lexical representations are needed to explain differences in performance on words and pseudowords. At this time, the conditions under which pseudowords show short-term masked repetition priming are unclear, but there is no doubt that pseudowords show long-term priming. Many of the pseudoword results that have been taken as evidence for the existence of lexical representations can also be explained within the episodic framework. For example, the fact that words are identified more readily than pseudowords can be attributed to the fact that episodes containing words already exist in memory, but episodes containing pseudowords do not. In addition, the assumption that episodic retrieval is similarity-based allows the episodic approach to explain the finding that the amount of repetition priming shown by nonwords depends on the extent to which they resemble real words. Furthermore, some word-pseudoword differences that have been attributed to abstract representations may instead be due to differences in meaningfulness. The effects of retention interval and multiple repetitions on words and pseudowords are still unclear.

\section{Long-Term Morphological Priming}

Probably the strongest support for the abstractionist approach comes from research investigating long-term priming between morphologically related words. In these experiments, subjects usually respond to targets (e.g., car) after studying a list that includes the target, a word that shares the same base morpheme as the target (e.g., cars) or a word that is orthographically similar to the target but does not share the same base morpheme (e.g., card). The basic finding is that long-term priming occurs only between morphological relatives; for example, studying cars facilitates perceptual identification of car but studying card does not (Murrell \& Morton, 1974; Napps \& Fowler, 1987). Furthermore, morphological priming persists long after the standard semantic priming effect has disappeared and, hence, qualifies as a distinct phenomenon (Napps, 1989).

Two results from this paradigm are especially problematic for the episodic approach. First, studying the inflected form of a target (e.g., managed vs. manage) produces about as much lexical decision priming as does studying the target itself (see, e.g., Feldman, 1994; Feldman \& Fowler, 1987; Fowler, Napps, \& Feldman, 1985; Napps, 1989). Typically, the target-target condition is slightly faster than the inflection-target condition, but statistically they do not differ. This finding contradicts the episodic approach, which predicts that the target should show more priming in the target-target condition because two presentations of the target should be more similar to each other than should a presentation of an inflection and the target. However, it is consistent with a version of the abstractionist view in which the lexicon is organized around morphemes. Thus, the representation for the base morpheme "manage" would be used to identify the words manage and managed; likewise, the representation for the base morpheme "car" would be used to identify the words car and cars.

The second result that causes problems for the episodic approach is that the amount of lexical decision priming that occurs between morphologically related words is not always reduced by changes in spelling or pronunciation (e.g., slept-sleep; Feldman \& Fowler, 
1987; Fowler et al., 1985; Napps, 1989). On the other hand, Napps (1989) found no long-term priming between verb pairs, such as go and went or catch and caught, suggesting that drastic differences in spelling and pronunciation can eliminate morphological priming. In addition, Murrell and Morton (1974) obtained more perceptual identification priming when the target had been studied than when a morphologically related word had been studied. Similarly, Downie, Milech, and Kirsner (1985, as cited in Kirsner et al., 1987) found more perceptual identification priming between derivations and bases when the base morpheme kept the same stress and pronunciation in both words (banishmentbanish) than when one or two phonemes differed (repress-repression; conceive-conception). However, the greatest amount of priming occurred when both stress and pronunciation changed (vegetate-vegetation) - a result that clearly contradicts the principle that priming should increase with similarity.

Thus, most of the morphological priming evidence favors an abstractionist account organized around morphemes. Still, the fact that some studies have found significant effects of sound and spelling changes, together with the tendency for inflections to prime bases slightly less than bases prime themselves, suggests that surface form similarity can play a small role in morphological priming. Rueckl and Dror's (1994) work suggests one means by which this could occur. As mentioned earlier, Rueckl and Dror found that pseudowords were easier to identify if there was a systematic relationship between their spellings and their meanings. This finding is consistent with a weakly episodic connectionist model that includes connections between orthographic and semantic units. Such a model might be capable of simulating morphological priming without explicitly representing morphemes. Further research is needed to explore this possibility.

\section{Summary of Evidence}

Abstractionist accounts of word identification attribute repetition priming to a temporary increase in the accessibility of a lexical unit. Several claims of this class of models have been challenged by the research reviewed here. First, abstractionist models assume that the accessibility of a lexical unit returns to normal within a relatively brief period of time. Although the short lifespan of masked repetition priming is consistent with this prediction, numerous studies using other paradigms have demonstrated significant priming after much longer delays.

Second, abstractionist models claim that the details of a specific occurrence of a word play no role in repetition priming. However, researchers have repeatedly found that priming is greater when the perceptual characteristics of a word are the same from one occurrence to the next; furthermore, there is some evidence that this result holds for episodic context as well.

Third, although pure abstractionist theories may be able to account for some of the pseudoword data, these data can also be explained by the episodic approach. Furthermore, the pure abstractionist approach suggests that pseudowords are identified via the lexical entries of the words that they resemble. However, as mentioned earlier, pure abstractionist theories cannot account for the long-term priming effects that have been found for words. Consequently, they also cannot account for the long-term priming effects that have been found for pseudowords.

Fourth, priming between morphologically related words seems best explained by an abstractionist view that is organized around morphemes. In particular, the finding that bases do not prime themselves significantly more than inflections prime their bases appears to contradict the episodic view. Moreover, inflections that change the spelling or pronunciation of the base (e.g., slept-sleep) can show as much priming as do inflections that preserve the spelling or pronunciation of the base. On the other hand, some studies have found significant effects of spelling and pronunciation changes, as predicted by the episodic approach. In addition, repetition priming for bases is often slightly greater than priming from inflections to bases.

\section{CONCLUSIONS}

Clearly, the evidence argues against a pure abstractionist account of word identification. Having drawn this conclusion, the next logical questions are: (1) Does a full account of the data require that abstract representations be posited at all? (2) If abstract representations are needed, are they fundamentally distinct from episodic representations (the weakly abstractionist view) or do they merely differ in level of generality (the weakly episodic view)?

\section{Do We Need Abstract Representations?}

Salasoo et al. (1985) argued that abstract lexical representations are needed to explain repetition priming for words because pure episodic models wrongly predict a strong relationship between priming and recognition memory. However, others (e.g., Jacoby, 1983b) have suggested that recognition memory and repetition priming could be largely independent if they tap different aspects of an episode. Furthermore, recognition memory and repetition priming are related under some conditions (e.g., W. A. Johnston et al., 1985). In any case, arguments concerning relationships between explicit and implicit memory tasks are difficult to evaluate in the absence of detailed theories that specify how these tasks are performed.

Taking a different tack, Brown and Carr (1993) argued that abstract representations are needed to explain the finding that changes in surface form do not always reduce priming. In particular, it is more difficult to find effects of repeating surface form when ordinary, typicallooking type is used. Nevertheless, as explained earlier, Brown and Carr's results can be accounted for by an epi- 
sodic word identification model analogous to Medin and Schaffer's (1978) context model of categorization. According to this view, one encounters many instances of words in typical-looking type, so a large number of highly similar episodes would be available to aid identification of a typical-looking word. In contrast, an unusuallooking handwritten word would resemble a few episodes; hence, repeating that word in its original surface form would considerably enhance its identification.

Still, one could argue that abstract representations are needed to account for the short-term repetition effect in the masked priming paradigm. However, it is conceivable that a pure episodic theory might be able to explain this effect. Other tasks, such as free recall and recognition memory, show disparate forgetting rates, yet both are assumed to tap memory for episodes. Thus, differential forgetting rates pose a general problem that memory theorists must solve. One approach is to assume that memory tasks vary in the retrieval cues that they provide (Tulving \& Thomson, 1973) or the kind of processing they invoke (Morris, Bransford, \& Franks, 1977). To the extent that memory theorists solve the general problem of differential forgetting rates, they may be able to explain why masked repetition priming has a much shorter lifespan than unmasked priming.

The role of episodic representations in masked repetition priming should become clearer when we learn the answers to several other questions. First, how is masked repetition priming affected by changes in surface form? Given the brief display times used in this paradigm, it seems likely that early visual processing is influenced. If same-form and changed-form primes are equally effective, it would strongly suggest that the perceptual features of the prime do not serve as retrieval cues for a visually similar prior occurrence of the word. Second, under what circumstances do pseudowords show masked repetition priming? Sereno (1991) and Rajaram and Neely (1992) obtained conflicting results for lexical de cisions to unstudied pseudowords. However, for reasons discussed earlier, the lexical decision task may not be appropriate for investigating repetition effects on pseudowords. Third, what is the relationship between masked repetition priming and masked form priming with nonidentical primes? The recent work of Forster and Taft (1994) suggests that masked form priming is determined by a complex combination of factors, including which sublexical constituents the prime and target share and how many other words share them. Hence, one possibility is that masked repetition priming is a special case of masked form priming in which all sublexical constituents are shared by the prime and target.

Finally, it has been argued that morphological priming effects must be mediated by abstract morphemic representations. Nevertheless, the work of Rueckl and Dror (1994) raises the possibility that morphological priming can be accounted for by a weakly episodic model. Specifically, a systematic relationship between spelling and meaning can be modeled using connections between semantic and orthographic units. Thus, it may be that these orthographic-semantic connections are responsible for morphological priming.

All things considered, there is currently no evidence that unequivocally demands that we posit abstract lexical representations in addition to specific episodes. However, some phenomena, such as short-term masked repetition priming and long-term morphological priming, may be easier to explain within a weakly abstractionist or weakly episodic framework than within a pure episodic framework.

\section{How Different Are Abstract and Episodic Representations?}

If abstract representations are posited, are they fundamentally different from episodic representations (as suggested by the weakly abstractionist approach), or do they just differ in level of generality (as suggested by the weakly episodic approach)? It is not clear how one could distinguish these alternatives empirically. Individual models within each approach could be evaluated, but none have been proposed in sufficient detail.

As mentioned earlier, Salasoo et al. (1985) and Brown and Carr (1989) argued strongly that abstract representations are needed to explain the data. However, a close reading reveals that they did not claim that abstract and episodic representations must be different in form. That is, their models could be implemented as either weakly abstractionist or weakly episodic models. In fact, Salasoo et al. explicitly stated that they considered McClelland and Rumelhart's (1985) weakly episodic distributed memory model to be compatible with their own view: "In that model, codification is an emergent behavioral consequence of superimposed memory traces laid down on presentations of words and pseudowords ... Indeed, it is compatible with our notion of a code as functionally discrete from the episodes related to it" (Salasoo et al., 1985 , p. 73). Similarly, Brown and Carr (1993, p. 1292) suggested that their account could be implemented in several ways, some of which would be considered weakly episodic.

A major challenge for future theories that posit both abstract and episodic representations is to explain how they interact. For example, Brown and Carr (1993) suggested that words are normally identified using abstract representations, but episodic representations can contribute if an unusual typography or handwriting is encountered. This proposal is consistent with either a weakly abstractionist or a weakly episodic theory. Advocates of a weakly abstractionist account would need to describe how the system determines when episodic information should be used. In addition, they would need to describe how the two kinds of information are combined. Finally, they would have to specify when and how an abstract lexical entry is formed.

Yet another problem to be solved by advocates of the weakly abstractionist approach concerns how it is determined which stimulus features should be retained and which features should be discarded so that the appropriate abstract code is activated. Traditionally, abstraction- 
ists have sidestepped this problem by assuming that some sort of normalization or feature extraction occurs at a lower level of processing, but they have not specified how this is accomplished. However, further specification is necessary to fully explain, for example, how variability in handwriting is accommodated.

For weakly episodic models, on the other hand, these problems are solved by the architecture. First, there is no need to specify how abstract representations are formed, because all levels of generality are represented in the connection weights. Furthermore, the retrieval cues that are present determine whether a relatively abstract or specific representation will be retrieved. Given distorted or incomplete input, connectionist networks can produce the appropriate pattern of output because the input cues and the weights on the connections between the units constrain the flow of activation in the network. This property, known as graceful degradation (McClelland, Rumelhart, \& Hinton, 1986), should allow connectionist models of word identification to accommodate variations in type fonts and handwriting if those models are extended to include feature-level information.

Modeling transfer between different tasks in a weakly episodic framework may pose a greater challenge. So far, connectionists have modeled performance on different tasks by showing that data from humans can be predicted by various statistics derived from the model. For example, Seidenberg and McClelland (1989) presented strings to their network, computed orthographic error scores, and used them to predict lexical decision performance. However, they did not actually model the performance of the task itself. Yet task modeling would seem to be necessary in order to explain why (for example) dissociations occur between implicit and explicit versions of tasks that provide identical physical cues (see Roediger \& McDermott, 1993, for a review of this research).

In summary, it is not clear what kind of evidence would distinguish between the weakly abstractionist and weakly episodic approaches to word identification. However, an advantage of weakly episodic accounts is that the solutions to several problems fall naturally out of the connectionist architecture.

\section{Pure Episodic Theories}

Very few pure episodic theories have been proposed in detail, perhaps because this approach emerged only recently. For pure episodic theories, a fundamental problem is to explain how the information contained in similar-yet not identical—episodes is adapted for use in the current situation. A possible solution is suggested by Logan's $(1988,1990)$ instance theory. Logan has proposed that tasks can be performed either by using an algorithm to compute a response or by retrieving an appropriate episode from memory. As an example, a simple multiplication problem such as $3 \times 3$ can be solved by adding 3 and 3 together and then adding 3 to the result or, if the problem has been encountered before, by directly retrieving the answer. It is further assumed that there is a race between computation by algorithms and retrieval from memory, with the winner performing the task. A record of this performance is then stored in memory. Retrieval is generally faster than computation, so the storage of additional useful records in memory increases the likelihood that one will retrieve a "fast" episode that can beat the algorithm. Thus, practice with an item causes a transition from slow algorithm-based performance to faster memory-based performance.

According to Logan (1990), one's first lexical decision to an item (e.g., camp) cannot be made by retrieval alone, because there are no appropriate episodes; instead, a response must be inferred from the information retrieved. In this case, the inference process corresponds to the algorithm. Consequently, the time needed to compute a response would include both the time needed to retrieve the information that serves as the basis for the inference and the time needed to actually make the inference. A record of this performance is stored in memory. Then, when camp is tested again, a decision can be made either by retrieving that record or by going through the inferencing process again, but the retrieval process is likely to win the race now that an appropriate episode is available.

In most of Logan's (1988, 1990; Grant \& Logan, 1993) experiments, the subjects' first exposure to an item occurred in the same task that was used for subsequent presentations. Yet, in many repetition priming experiments, the subjects initially saw the items in a study list, then performed a different task with the items on their second presentation. Despite the task change, performance on recently presented items was facilitated relative to performance on new items. Fortunately, Logan's theory is easily extended to explain priming across tasks as follows: When a word such as camp is presented in a study list, a record of its processing is stored. Later, when camp is presented in a word identification task, it can be identified either by retrieving the study episode and applying an algorithm to infer the correct response or by retrieving an older episode and applying an algorithm to infer the correct response. If the retrieved episode resembles the test item, less work must be done by the algorithm, thus saving time. Consequently, to the extent that the study episode resembles the test item more strongly than does the older episode, responses to a studied item will be facilitated. Note that this extension of Logan's theory can also explain why repetition priming is greater when an item's original surface features are repeated. Furthermore, it explains why the effects of repeating surface features are larger for low-frequency words and for items presented in an unusual typography or handwriting. It remains to be seen whether Logan's theory can account for short-term masked repetition priming and priming between morphologically related words.

In summary, the data indicate that episodic representations are used to identify words. These results rule out pure abstractionist theories of word identification. In fact, there is no clear evidence that abstract representa- 
tions are used at all, and it may be possible to account for the data without them. However, some phenomena may be easier to explain if both types of representations are posited. At this point, what is needed are detailed word identification models that can be pitted against one another.

Formulating detailed models of performance on word identification tasks should also further our understanding of performance on other implicit memory tasks, such as word fragment completion and word stem completion. These tasks were excluded from the current review because they probably invoke extended problemsolving processes in addition to normal word identification processes. Nevertheless, they resemble word identification tasks in showing long-lived priming effects that are partially modality-specific. Moreover, these tasks also resemble word identification tasks in showing dissociations from explicit memory tasks in both normal subjects and amnesic patients (see Roediger \& McDermott, 1993; also see Moscovitch, Goshen-Gottstein, \& Vriezen, 1994).

Finally, as mentioned at the beginning of this paper, recent work suggests that specific instances play a role in categorization and problem-solving tasks. Logan (1990) has pointed out that the success of instance theories across domains raises "the possibility that a single, general instance theory can account for a broad range of cognitive phenomena" (p. 32). Developing a successful episodic theory of performance on word identification tasks and extending it to other implicit and explicit memory tasks would represent a great leap toward the goal of a general instance theory.

\section{REFERENCES}

ANDERSon, J. R., \& Ross, B. H. (1980). Evidence against a semanticepisodic distinction. Journal of Experimental Psychology: Human Learning \& Memory, 6, 441-466.

BainBRidGe, J. V., LeWANDOWSKY, S., \& KIRSNER, K. (1993). Context effects in repetition priming are sense effects. Memory \& Cognition; 21, 619-626.

BECKER, C. A. (1980). Semantic context effects in visual word recognition: An analysis of semantic strategies. Memory \& Cognition, 8 , 493-512.

BESNER, D., \& SwAN, M. (1982). Models of lexical access in visual word recognition. Quarterly Journal of Experimental Psychology, 34A, 313-325.

Bowers, J. S. (1994). Does implicit memory extend to legal and illegal nonwords? Journal of Experimental Psychology: Learning, Memory, \& Cognition, 20, 534-549.

BROOKs, L. R. (1978). Nonanalytic concept formation and memory for instances. In E. Rosch \& B. B. Lloyd (Eds.), Cognition and categorization (pp. 169-211). New York: Wiley.

Brown, J. S., \& CARR, T. H. (1993). Limits on perceptual abstraction in reading: Asymmetric transfer between surface forms differing in typicality. Journal of Experimental Psychology: Learning, Memory, \& Cognition, 19, 1277-1296.

Carlson, L. A., Alejano, A. R., \& Carr, T. H. (1991). The level-offocal attention hypothesis in oral reading: Influence of strategies on the context specificity of lexical repetition effects. Journal of Experimental Psychology: Learning, Memory, \& Cognition, 17, 924931.

CARr, T. H., \& Brown, J. S. (1990). Perceptual abstraction and inter- activity in repeated oral reading: Where do things stand? Journal of Experimental Psychology: Learning, Memory, \& Cognition, 16, $731-738$.

Carr, T. H., Brown, J. S., \& Charalambous, A. (1989). Repetition and reading: Perceptual encoding mechanisms are very abstract but not very interactive. Journal of Experimental Psychology: Learning, Memory, \& Cognition, 15, 763-778.

CARR, T. H., \& PollatSEK, A. (1985). Recognizing printed words: A look at current models. In D. Besner, K. G. Waller, \& E. M. MacKinnon (Eds.), Reading research: Advances in theory and practice (Vol. 5, pp. 1-81). Toronto: Academic Press.

Carroll, M., \& Kirsner, K. (1982). Context and repetition effects in lexical decision and recognition memory. Journal of Verbal Learning \& Verbal Behavior, 21, 55-69.

Church, B. A., \& SChacter, D. L. (1994). Perceptual specificity of auditory priming: Implicit memory for voice intonation and fundamental frequency. Journal of Experimental Psychology: Learning, Memory, \& Cognition, 20, 521-533.

Clarke, R., \& Morton, J. (1983). Cross-modality facilitation in tachistoscopic word recognition. Quarterly Journal of Experimental Psychology, 35A, 79-96.

Coltheart, M. (1980). Reading, phonological recoding, and deep dyslexia. In M. Coltheart, K. Patterson, \& J. Marshall (Eds.), Deep dyslexia (pp. 197-226). London: Routledge \& Kegan Paul.

Coltheart, M., Curtis, B., Atkins, P., \& Haller, M. (1993). Models of reading aloud: Dual-route and parallel-distributed processing approaches. Psychological Review, 100, 589-608.

CraIK, F. I. M. (1991). On the specificity of procedural memory. In W. Kessen, A. Ortony, \& F. I. M. Craik (Eds.), Memories, thoughts, and emotions: Essays in honor of George Mandler (pp. 183-197). Hillsdale, NJ: Erlbaum.

Dannenbring, G. L., \& Briand, K. (1982). Semantic priming and the word repetition effect in a lexical decision task. Canadian Journal of Psychology, 36, 435-444.

DEN HEYER, K. (1986). Manipulating attention-induced priming in a lexical decision task by means of repeated prime-target presentations. Journal of Memory \& Language, 25, 19-42.

DORFMAN, J. (1994). Sublexical components in implicit memory for novel words. Journal of Experimental Psychology: Learning, Memory, \& Cognition, 20, 1108-1125.

DUCHEK, J. M., \& NEELY, J. H. (1989). A dissociative word-frequency $x$ levels-of-processing interaction in episodic recognition and lexical decision tasks. Memory \& Cognition, 17, 148-162.

DURGUNơ̆LU, A. Y. (1988). Repetition, semantic priming, and stimulus quality: Implications for the interactive-compensatory reading model. Journal of Experimental Psychology: Learning, Memory, \& Cognition, 14, 590-603.

DuRgunơ̌lu, A. Y., \& NeELY, J. H. (1987). On obtaining episodic priming in a lexical decision task following paired-associate learning. Journal of Experimental Psychology: Learning, Memory, \& Cognition, 13, 206-222.

DuRso, F. T., \& Johnson, M. K. (1979). Facilitation in naming and categorizing repeated pictures and words. Journal of Experimental Psychology: Human Learning \& Memory, 5, 449-459.

Feldman, L. B. (1994). Beyond orthography and phonology: Differences between inflections and derivations. Journal of Memory \& Language, 33, 442-470.

Feldman, L. B., \& Fowler, C. A. (1987). The inflected noun system in Serbo-Croatian: Lexical representation of morphological structure. Memory \& Cognition, 15, 1-12.

Feustel, T. C., Shiffrin, R. M., \& Salasoo, A. (1983). Episodic and lexical contributions to the repetition effect in word identification. Journal of Experimental Psychology: General, 112, 309-346.

Forbach, G. B., STANNERs, R. F., \& HochHaus, L. (1974). Repetition and practice effects in a lexical decision task. Memory \& Cognition, 2, 337-339.

FORSTER, K. I. (1987). Form-priming with masked primes: The best match hypothesis. In M. Coltheart (Ed.), Attention and performance XII: The psychology of reading (pp. 127-145). London: Erlbaum. 
Forster, K. I., \& Davis, C. (1984). Repetition priming and frequency attenuation in lexical access. Journal of Experimental Psychology: Learning, Memory, \& Cognition, 10, 680-698.

FORSTER, K. I., \& TAFT, M. (1994). Bodies, antibodies, and neighborhood-density effects in masked form priming. Journal of Experimental Psychology: Learning, Memory, \& Cognition, 20, 844-863.

Fowler, C. A., NAPPs, S. E., \& Feldman, L. B. (1985). Relations among regular and irregular morphologically related words in the lexicon as revealed by repetition priming. Memory \& Cognition, 13, 241-255.

GLushko, R. J. (1979). The organization and activation of orthographic knowledge in reading aloud. Journal of Experimental Psychology: Human Perception \& Performance, 5, 674-69l.

Goshen-Gottstein, Y., \& Moscovitch, M. (in press). Repetition priming for newly-formed and preexisting associations: Perceptual and conceptual influences. Journal of Experimental Psychology: Learning, Memory, \& Cognition.

Graf, P., \& Levy, B. A. (1984). Reading and remembering: Conceptual and perceptual processing involved in reading rotated passages. Journal of Verbal Learning \& Verbal Behavior, 23, 405-424.

GRAF, P., \& RYAN, L. (1990). Transfer-appropriate processing for implicit and explicit memory. Journal of Experimental Psychology: Learning, Memory, \& Cognition, 16, 978-992.

GRAF, P., \& SCHACTER, D. L. (1985). Implicit and explicit memory for new associations in normal and amnesic subjects. Journal of Experimental Psychology: Learning, Memory, \& Cognition, 11, 501-518.

Grant, S. C., \& Logan, G. D. (1993). The loss of repetition priming and automaticity over times as a function of degree of initial learning. Memory \& Cognition, 21, 611-618.

HintzMan, D. L. (1986). Schema abstraction in a multiple trace model. Psychological Review, 93, 411-428.

HORTON, K. D. (1985). The role of semantic information in reading spatially-transformed text. Cognitive Psychology, 17, 66-88.

Humphreys, G. W., Besner, D., \& Quinlan, P. T. (1988). Event perception and the word repetition effect. Journal of Experimental Psychology: General, 117, 51-67.

Humphreys, G. W., EveTt, L. J., Quinlan, P. T., \& Besner, D. (1987). Orthographic priming: Qualitative differences between priming from identified and unidentified primes. In M. Coltheart (Ed.), Attention and performance XII: The psychology of reading (pp. 105126). London: Erlbaum.

JACKSON, A., \& MORTON, J. (1984). Facilitation of auditory word recognition. Memory \& Cognition, 12, 568-574.

JACOBY, L. L. (1983a). Perceptual enhancement: Persistent effects of an experience. Journal of Experimental Psychology: Learning, Memory, \& Cognition, 9, 21-38.

JACOBY, L. L. (1983b). Remembering the data: Analyzing interactive processes in reading. Journal of Verbal Learning \& Verbal Behavior, 22, 485-508.

JACOBY, L. L., \& BROOKS, L. (1984). Nonanalytic cognition: Memory, perception, and concept learning. In G. H. Bower (Ed.), The psychology of learning and motivation: Advances in research and theory (Vol. 18, pp. 1-47). San Diego, CA: Academic Press.

JACOBY, L. L., \& Dallas, M. (1981). On the relationship between autobiographical memory and perceptual learning. Journal of Experimental Psychology: General, 110, 306-340.

JACOBY, L. L., \& HAYMAN, C. A. G. (1987). Specific visual transfer in word identification. Journal of Experimental Psychology: Learning, Memory, \& Cognition, 13, 456-463.

JaCoBy, L. L., LeVY, B. A., \& SteinBaCh, K. (1992). Episodic transfer and automaticity: Integration of data-driven and conceptuallydriven processing in reading. Journal of Experimental Psychology: Learning, Memory, \& Cognition, 18, 15-24.

JACOBY, L. L., \& WhITEHOUSE, K. (1989). An illusion of memory: False recognition influenced by unconscious perception. Journal of Experimental Psychology: General, 118, 126-135.

JACOBY, L. L., \& WiThERSPOON, D. (1982). Remembering without awareness. Canadian Journal of Psychology, 36, 300-324.

Johnson, N. F., \& Pugh, K. R. (1994). A cohort model of visual word recognition. Cognitive Psychology, 26, 240-346.

Johnston, J. C., van SANTEN, J. P. H., \& Hale, B. L. (1985). Repetition effects in word and pseudoword identification: Comment on
Salasoo, Shiffrin, and Feustel. Journal of Experimental Psychology: General, 114, 498-508.

Johnston, W. A., Dark, V. J., \& JaCOBY, L. L. (1985). Perceptual fluency and recognition judgments. Journal of Experimental Psychology: Learning, Memory, \& Cognition, 11, 3-11.

KiRSNER, K., DUNN, J., \& STANDEN, P. (1987). Record-based word recognition. In M. Coltheart (Ed.), Attention and performance XII: The psychology of reading (pp. 147-167). Hillsdale, NJ: Erlbaum.

KiRSNER, K., \& SMITH, M. C. (1974). Modality effects in word identification. Memory \& Cognition, 2, 637-640.

Kolers, P. A. (1975). Specificity of operations in sentence recognition. Cognitive Psychology, 1, 289-306.

KOLERS, P. A. (1976). Reading a year later. Journal of Experimental Psychology: Human Learning \& Memory, 2, 554-565.

Kolers, P. A., \& OSTRY, D. J. (1974). Time course of loss of information regarding pattern analyzing operations. Journal of Verbal Learning \& Verbal Behavior, 13, 599-612.

Kolers, P. A., \& Perkins, D. N. (1975). Spatial and ordinal components of form perception and literacy. Cognitive Psychology, 7, 228-267.

Kolers, P. A., \& Roediger, H. L., III (1984). Procedures of mind. Journal of Verbal Learning \& Verbal Behavior, 23, 425-449.

Levy, B. A. (1983). Proofreading familiar text: Constraints on visual processing. Memory \& Cognition, 11, 1-12.

LEvy, B. A., \& Begin, J. (1984). Proofreading familiar text: Allocating resources to perceptual and conceptual processes. Memory \& Cognition, 12, 621-632.

LEVY, B. A., \& BuRNs, K. I. (1990). Reprocessing text: Contributions from conceptually driven processes. Canadian Journal of Psychology, 44, 465-482.

Levy, B. A., DiPersio, R., \& Hollingshead, A. (1992). Fluent rereading: Repetition, automaticity, and discrepancy. Journal of Experimental Psychology: Learning, Memory, \& Cognition, 18, 957-971.

LEVY, B. A., \& KIRSNER, K. (1989). Reprocessing text: Indirect measures of word and message level processes. Journal of Experimental Psychology: Learning, Memory, \& Cognition, 15, 407-417.

Levy, B. A., Masson, M. E. J., \& ZoubEK, M. A. (1991). Rereading text: Words and their context. Canadian Journal of Psychology, 45, 492-506

Levy, B. A., Newell, S., Snyder, J., \& Timmins, K. (1986). Processing changes across reading encounters. Journal of Experimental Psychology: Learning, Memory, \& Cognition, 12, 467-478.

LEWANDOWSKY, S. (1991). Gradual unlearning and catastrophic interference: A comparison of distributed architectures. In W. E. Hockley \& S. Lewandowsky (Eds.), Relating theory and data: Essays on human memory in honor of Bennet B. Murdock (pp. 445-476). Hillsdale, NJ: Erlbaum.

Lewandowsky, S., KirSner, K., \& Bainbridge, J. V. (1989). Context effects in implicit memory: A sense-specific account. In S. Lewandowsky, J. C. Dunn, \& K. Kirsner (Eds.), Implicit memory: Theoretical issues (pp. 185-198). Hillsdale, NJ: Erlbaum.

LogAN, G. D. (1988). Toward an instance theory of automatization. Psychological Review, 95, 492-527.

LoGAN, G. D. (1990). Repetition priming and automaticity: Common underlying mechanisms? Cognitive Psychology, 22, 1-35.

lukatela, G., Turvey, M. T., Feldman, L. B., Carello, C., \& KATZ, L. (1989). Alphabet priming in bi-alphabetical word perception. Journal of Memory \& Language, 28, 237-254.

Manso de Zuniga, C., Humphreys, G. W., \& Evett, L. J. (1991). Additive and interactive effects of repetition, degradation, and word frequency in the reading of handwriting. In D. Besner \& G. W. Humphreys (Eds.), Basic processes in reading: Visual word recognition (pp. 10-33). Hillsdale, NJ: Erlbaum.

Masson, M. E. J. (1984). Memory for the surface structure of sentences: Remembering with and without awareness. Journal of Verbal Learning \& Verbal Behavior, 23, 579-592.

MASSON, M. E. J. (1986). Identification of typographically transformed words: Instance-based skill acquisition. Journal of Experimental Psychology: Learning, Memory, \& Cognition, 12, 479-488.

Masson, M. E. J., \& FreEdMAN, L. (1990). Fluency in the identification of repeated words. Journal of Experimental Psychology: Learning, Memory, \& Cognition, 16, 355- 373. 
Masson, M. E. J., \& MACLeOD, C. M. (1992). Re-enacting the route to interpretation: Enhanced perceptual identification without prior perception. Journal of Experimental Psychology: General, 121, 145-176.

MCClelland, J. L., \& Rumelhart, D. E. (1981). An interactive model of context effects in letter perception: Part 1. An account of basic findings. Psychological Review, 88, 375-405.

McClelland, J. L., \& Rumelhart, D. E. (1985). Distributed memory and the representation of general and specific information. Journal of Experimental Psychology: General, 114, 159-188.

MCClelland, J. L., Rumelhart, D. E., \& Hinton, G. E. (1986). The appeal of parallel distributed processing. In D. E. Rumelhart, J. L. McClelland, \& the PDP Research Group (Eds.), Parallel distributed processing: Vol. I. Foundations (pp. 3-44). Cambridge, MA: MIT Press.

MCCloskey, M., \& COHEN, N. J. (1989). Catastrophic interference in connectionist networks: The sequential learning problem. In G. H. Bower (Ed.), The psychology of learning and motivation (Vol. 24, pp. 109-164). New York: Academic Press

MCKoon, G., \& RATCLIfF, R. (1979). Priming in episodic and semantic memory. Journal of Verbal Learning \& Verbal Behavior, 18 , 463-480.

MCKoON, G., \& RaTCLIFF, R. (1986). Automatic activation of episodic information in a semantic memory task. Journal of Experimental Psychology: Learning, Memory, \& Cognition, 12, 108-115.

Medin, D. L., Altom, M. W., Edelson, S. M., \& Freko, D. (1982). Correlated symptoms and simulated medical classification. Journal of Experimental Psychology: Learning, Memory, \& Cognition, 8, $37-50$

Medin, D. L., \& Schaffer, M. M. (1978). Context theory of classification learning. Psychological Review, 85, 207-238.

Morris, C. D., BRANSFord, J. D., \& FranKS, J. J. (1977). Levels of processing versus transfer appropriate processing. Journal of Verbal Learning \& Verbal Behavior, 16, 519-533.

MORTON, J. (1969). Interaction of information in word recognition. Psychological Review, 76, 165-178.

MorToN, J. (1979). Facilitation in word recognition: Experiments causing change in the logogen model. In P. A. Kolers, M. E. Wrolstad, \& H. Bouma (Eds.), Processing visible language I (pp. 259. 268). New York: Plenum.

Moscovitch, M., Goshen-Gottstein, Y., \& VRiezen, E. (1994). Memory without conscious recollection: A tutorial review from a neuropsychological perspective. In C. Umiltà \& M. Moscovitch (Eds.), Attention and performance XV: Conscious and nonconscious information processing (pp. 619-660). Cambridge, MA: MIT Press.

MURRELl, G. A., \& MoRToN, J. (1974). Word recognition and morphemic structure. Journal of Experimental Psychology, 102, 963968.

NAPPS, S. E. (1989). Morphemic relationships in the lexicon: Are they distinct from semantic and formal relationships? Memory \& Cognition, 17, 729-739.

NAPPS, S. E., \& FowleR, C. A. (1987). Formal relationships among words and the organization of the mental lexicon. Journal of Psycholinguistic Research, 16, 257-272.

NeEly, J. H., \& DurgunoĞLU, A. Y. (1985). Dissociative episodic and semantic priming effects in episodic recognition and lexical decision tasks. Journal of Memory \& Language, 24, 466-489.

Posner, M. I., \& Keele, S. W. (1968). On the genesis of abstract ideas. Journal of Experimental Psychology, 77, 353-363.

Rajaram, S., \& Neely, J. H. (1992). Dissociative masked repetition priming and word frequency effects in lexical decision and episodic recognition tasks. Journal of Memory \& Language, 31, 152-182.

RATCLIFF, R. (1990). Connectionist models of recognition memory: Constraints imposed by learning and forgetting functions. Psychological Review, 97, 285-308.

REED, S. K. (1972). Pattern recognition and categorization. Cognitive Psychology, 3, 382-407.

ROEDIGER, H. L., III, \& MCDERMotT, K. B. (1993). Implicit memory in normal human subjects. In F. Boller \& J. Grafman (Eds.), Hand book of neuropsychology (Vol. 2, pp. 63-131). Amsterdam: Elsevier.

Roediger, H. L., III, Weldon, M. S., \& Challis, B. A. (1989). Explaining dissociations between implicit and explicit measures of re- tention. In H. L. Roediger III \& F. I. M. Craik (Eds.), Varieties of memory and consciousness: Essays in honour of Endel Tulving (pp. 3-41). Hillsdale, NJ: Eribaum.

Ross, B. H. (1984). Remindings and their effects in learning a cognitive skill. Cognitive Psychology, 16, 371-416.

Ross, B. H. (1987). This is like that: The use of earlier problems and the separation of similarity effects. Journal of Experimental Psychology: Learning, Memory, \& Cognition, 13, 629-639.

Rosson, M. B. (1983). From SOFA to LOUCH: Lexical contributions to pseudoword pronunciation. Memory \& Cognition, 11, 152-160.

Rosson, M. B. (1985). The interaction of pronunciation rules and lexical representations in reading aloud. Memory \& Cognition, 13, 90-99.

RUECKL, J. G. (1990). Similarity effects in word and pseudoword repetition priming. Journal of Experimental Psychology: Learning. Memory, \& Cognition, 16, 374-391.

RUECKL, J. G., \& DroR, I. E. (1994). The effect of orthographicsemantic systematicity on the acquisition of new words. In C. Umiltà \& M. Moscovitch (Eds.), Attention and performance XV. Conscious and nonconscious information processing (pp. 571-588). Cambridge, MA: MIT Press.

RuECKL, J. G., \& OlDs, E. M. (1993). When pseudowords acquire meaning: Effect of semantic associations on pseudoword repetition priming. Journal of Experimental Psychology: Learning, Memory, \& Cognition, 19, 515-527.

Salasoo, A., Shiffrin, R. M., \& Feustel, T. C. (1985). Building permanent memory codes: Codification and repetition effects in word identification. Journal of Experimental Psychology: General, 114, 50-77.

Scarborough, D. L., Cortese, C., \& SCarborough, H. (1977). Frequency and repetition effects in lexical memory. Journal of Experimental Psychology: Human Perception \& Performance, 3, 1-17

SCHACTER, D. L., \& CHURCH, B. A. (1992). Auditory priming: Implicit and explicit memory for words and voices. Journal of Experimental Psychology: Learning, Memory, \& Cognition, 18, 915-930.

Seidenkerg, M. S., \& McClelland, J. L. (1989). A distributed, developmental model of word recognition and naming. Psychological Review, 96, 523-568.

SEreno, J. A. (1991). Graphemic, associative, and syntactic priming effects at a brief stimulus onset asynchrony in lexical decision and naming. Journal of Experimental Psychology: Learning, Memory, \& Cognition, 17, 459-477.

Smith, M. C., MacLeod, C. M., Bain, J. D., \& Hoppe, R. B. (1989) Lexical decision as an indirect test of memory: Repetition and listwide priming as a function of type of encoding. Journal of Experimental Psychology: Learning, Memory, \& Cognition, 15, 1109. 1118.

TAFT, M., \& Forster, K. I. (1976). Lexical storage and retrieval of polymorphemic and polysyllabic words. Journal of Verbal Learning \& Verbal Behavior, 15, 607-620.

TARDIF, T., \& CraIK, F. I. M. (1989). Reading a week later: Perceptual and conceptual factors. Journal of Memory \& Language, 28, 107-125.

TOTH, J. P., \& HuNT, R. R. (1990). Effect of generation on a wordidentification task. Journal of Experimental Psychology: Learning, Memory, \& Cognition, 16, 993-1003.

Tulving, E. (1972). Episodic and semantic memory. In E. Tulving \& W. Donaldson (Eds.), Organization of memory (pp. 381-403). New York: Academic Press.

Tulving, E. (1983). Elements of episodic memory. Oxford: Oxford University Press.

Tulving, E. (1985). How many memory systems are there? American Psychologist, 40, 385-398.

Tulving, E., Schacter, D. L., \& Stark, H. A. (1982). Priming effects in word-fragment completion are independent of recognition memory. Journal of Experimental Psychology: Learning, Memory, \& Cognition, 8, 336-342.

Tulving, E., \& Thomson, D. M. (1973). Encoding specificity and retrieval processes in episodic memory. Psychological Review, 80, 352-373.

Warrington, E. K., \& Weiskrantz, L. (1968). New method of testing long-term retention with special reference to amnesic patients. Nature, 217, 972-974

Warrington, E. K., \& WeISKRantz, L. (1974). The effect of prior 
learning on subsequent retention in amnesic patients. Neuropsychologia, 12, 419-428.

WELDON, M. S. (1991). Mechanisms underlying priming on perceptual tests. Journal of Experimental Psychology: Learning, Memory, \& Cognition, 17, 526-541.

WhITLOW, J. W. (1990). Differential sensitivity of perceptual identification for words and pseudowords to test expectations: Implications for the locus of word frequency effects. Journal of Experimental Psychology: Learning, Memory, \& Cognition, 16, 837-851

Whitlow, J. W., \& Cebollero, A. (1989). The nature of word frequency effects in perceptual identification. Journal of Experimental Psychology: Learning, Memory, \& Cognition, 15, 643-656.

WhitTleseA, B. W. A. (1990). Perceptual encoding mechanisms are tricky but may be very interactive: Comment on Carr, Brown, and Charalambous (1989). Journal of Experimental Psychology: Learning, Memary, \& Cognition, 16, 727-730.

Whittlesea, B. W. A., \& BRooks, L. R. (1988). Critical influence of particular experiences in the perception of letters, words and phrases. Memory \& Cognition, 16, 387-399.

Whittlesea, B. W. A., \& Cantwell, A. L. (1987). Enduring influence of the purpose of experiences: Encoding-retrieval interactions in word and pseudoword perception. Memory \& Cognition, 15, 465472.

WoLTZ, D. J. (1990). Repetition of semantic comparisons: Temporary and persistent priming effects. Journal of Experimental Psychology: Learning. Memory, \& Cognition, 16, 392-403.

\section{NOTES}

1. I prefer the term "word identification" rather than the more traditional "word recognition," because it avoids confusion with the recognition memory task in which subjects are asked to judge whether particular words were encountered earlier in an experiment.

2. My use of the terms weakly abstractionist and weakly episodic differs slightly from that of Brown and Carr (1993). The discussion on page 1292 of their article makes it clear that their "weakly abstractionist" theory could be implemented as either a weakly abstractionist model or a weakly episodic model.

3. Kolers and Perkins (1975) calculated percentage transfer, or training potency, as follows:

$$
\text { Percentage transfer }=100(A-X) /(A-B),
$$

where $A$ is the average time taken on the first two training pages of a transformation by the group of readers trained on that transformation, $B$ is their average time on that transformation on days 5 and 6 (Test days), and $X$ is the amount of time taken by another group of readers, trained on a different trans- formation but reading the first transformation on the Test days. . . With this method of calculation percentage transfer to test pages (days 5 and 6) in the transformation on which training was received is always $100 \%$. (p. 237)

4. Tardif and Craik's (1989) experiments employed normally oriented type, inverted type, mirror-image type, and a fourth typography in which words were spelled backwards (see Figure 1). As Tardif and Craik acknowledged, transfer between these typographies ranged from $28 \%$ to $95 \%$ in the Kolers and Perkins (1975) study. Graf and Ryan's (1990) backwards type and upside-down type correspond to Kolers and Perkins' (1975) rM type and R type, respectively. Kolers and Perkins found greater transfer from backwards type to upside-down type $(67 \%)$ than from upside-down type to backwards type $(41 \%)$.

5 . There was no condition in which a word appeared in the same case on all four presentations. In another condition, called the $2 \mathrm{P}$ condition, case was shifted between the first and second presentations of a word. In the four-presentation (4P) condition mentioned in the text, case was not changed until the fourth presentation. Therefore, the effect of case change on the second presentation of a word can be determined by comparing priming in the $2 \mathrm{P}$ condition with priming in the 4P condition. Unfortunately, Feustel et al. (1983) did not assess this effect statistically. However, Figure 2 in their article suggests a slight same-font advantage if one takes into account the differing baselines in the $\mathrm{P} 2$ and $\mathrm{P} 4$ conditions.

6. Masson and Freedman (1990) argued that subjects would be unlikely to use the cued-recall strategy because there were so few trials on which the prime and target were both repeated. This is a reasonable point. Nevertheless, the argument would be more convincing if there had been some trials in which a studied prime was followed by either an unstudied target or a target that had been studied with a different prime.

7. These experiments often included a third condition in which sub jects used the context word to generate the target, but the target wa never visually presented. Because abstractionist theories posit separat lexicons for spoken and written words (see Note 2), this condition $i$ not directly relevant to the abstractionist-episodic debate.

8. Forster (1985, as cited in Rajaram \& Neely, 1992) also examiner masked repetition priming for pseudowords. However, as Rajaram anı Neely pointed out, some of the pseudowords were actually obsoletı words for which the subjects learned definitions and for which the cor rect lexical decision response was "word." The pseudowords for whicl the correct response was "nonword" were presented without definitions. Consequently, Forster's pseudoword results are difficult tc interpret.

(Manuscript received August 15, 1994; revision accepted for publication February 9, 1995.) 